\title{
Mechanisms of Eddy-Driven Variability of the Florida Current ${ }^{\mathscr{O}}$
}

\author{
RICARDO M. DOMINGUES \\ Cooperative Institute for Marine and Atmospheric Studies, University of Miami, Miami, Florida \\ WILLIAM E. JOHNS \\ Rosenstiel School of Marine and Atmospheric Science, University of Miami, Miami, Florida
}

CHRISTOPHER S. MEINEN

NOAA Atlantic Oceanographic and Meteorological Laboratory, Miami, Florida

(Manuscript received 24 September 2018, in final form 4 February 2019)

\begin{abstract}
In this study, mechanisms causing year-to-year changes in the Florida Current seasonality are investigated using controlled realistic numerical experiments designed to isolate the western boundary responses to westward-propagating open ocean signals. The experiments reveal two distinct processes by which westwardpropagating signals can modulate the phase of the Florida Current variability, which we refer to as the "direct" and "indirect" response mechanisms. The direct response mechanism involves a two-stage response to open ocean anticyclonic eddies characterized by the direct influence of Rossby wave barotropic anomalies and baroclinic wall jets that propagate through Northwest Providence Channel. In the indirect response mechanism, open ocean signals act as small perturbations to the stochastic Gulf Stream variability downstream, which are then transmitted upstream to the Florida Straits through baroclinic coastally trapped signals that can rapidly travel along the U.S. East Coast. Experiments indicate that westward-propagating eddies play a key role in modulating the phase of the Florida Current variability, but not the amplitude, which is determined by its intrinsic variability in our simulations. Results from this study further suggest that the Antilles Current may act as a semipermeable barrier to incoming signals, favoring the interaction through the indirect response mechanism. The mechanisms reported here can be potentially linked to year-to-year changes in the seasonality of the Atlantic meridional overturning circulation and may also be present in other western boundary current systems.
\end{abstract}

\section{Introduction}

The Florida Current (FC) is a western boundary current that feeds into the Gulf Stream, closing the subtropical gyre circulation in the North Atlantic Ocean. These currents play a central role in the northward transport of mass and heat within the upper limb of the Atlantic meridional overturning circulation (AMOC), a key component of Earth's climate system. Together, the FC and Gulf Stream are perhaps the most widely studied

\footnotetext{
Supplemental information related to this paper is available at the Journals Online website: https://doi.org/10.1175/JPO-D-180192.s1.
}

Corresponding author: Ricardo M. Domingues, rdomingues@ rsmas.miami.edu western boundary currents in the world's oceans (e.g., Pillsbury 1887, 1890; Stommel 1958; Richardson and Schmitz 1965; Wunsch et al. 1969; Baringer and Larsen 2001; Beal et al. 2008; Meinen et al. 2010; Rossby et al. 2010). Despite being the subject of innumerable studies, many questions still remain about the mechanisms driving the FC and Gulf Stream variability. The variability of the FC and Gulf Stream has been demonstrated in models to be associated with important climate and societal issues, including sea level changes and flooding events along the East Coast of the United States (Ezer 2013; Ezer and Atkinson 2014; Sweet et al. 2016). Therefore, knowledge on the specific mechanisms and processes causing changes in their flow is of importance for understanding the regional climate and managing coastal resilience.

The FC exhibits large temporal variability, with changes in volume transport on the order of $\pm 10 \mathrm{~Sv}$ 
$\left(1 \mathrm{~Sv}=10^{6} \mathrm{~m}^{3} \mathrm{~s}^{-1}\right)$ about a long-term mean value of $32 \mathrm{~Sv}$ (e.g., Schott et al. 1988; Meinen et al. 2010). The largeamplitude changes in the FC transport are believed to be caused by multiple drivers from which wind forcing is often described as the most important. For example, changes in large-scale atmospheric modes and winds (e.g., Baringer and Larsen 2001; Meinen et al. 2010; DiNezio et al. 2009), local winds (e.g., Wunsch et al. 1969; Beal et al. 2008) and in the wind stress curl upstream or downstream from the Florida Straits (e.g., Schott et al. 1988) have been pointed as key drivers of the FC variability on various time scales. The role of storms and hurricanes occurring at or off the coast have also been identified in recent studies (e.g., Ezer et al. 2017; Todd et al. 2018) as relevant drivers of seasonal and interannual FC and Gulf Stream variability that may cause a temporary disruption in their transport as large as $50 \%$ of the flow. In addition, since about $12 \mathrm{~Sv}$ of the FC transport contributes to the upper limb of the AMOC (e.g., Stommel 1958; Atkinson et al. 2010), large-scale wind driven changes in the AMOC (e.g., Zhao and Johns 2014) may also account for part of the large-amplitude FC variability.

Among the different time scales associated with the FC variability, seasonal changes have often been studied, with the annual cycle generally being characterized as having a peak-to-peak amplitude of about $4 \mathrm{~Sv}$, with maximum transport in July (Niiler and Richards 1973; Leaman et al. 1987; Schott et al. 1988; Baringer and Larsen 2001; Meinen et al. 2010). Previous analyses of long-term FC transport observations have suggested that there might be quasi-pentadal/quasi-decadal variations in the seasonality of the FC transport (Baringer and Larsen 2001; Atkinson et al. 2010). Later work found that these changes in the FC annual cycle are actually the result of background stochastic variability that is not directly linked to atmospheric forcing (Meinen et al. 2010), which has been termed the "transient" seasonal component of the FC transport (Domingues et al. 2016). Domingues et al. (2016) found that these transient seasonal variations account for $27 \%$ of the total FC variability, which is over three times larger than the contribution from the average annual cycle ( $8 \%$ of the total variability).

There is general agreement within the literature that the "average" FC annual variability is driven by a combination of along-channel winds and wind stress curl upstream and downstream of the Florida Straits (i.e., in the Caribbean Sea and in the Gulf Stream east of the Carolinas, respectively; e.g., Schott et al. 1988). Several recent studies have started to provide a better understanding of the possible causes for the transient changes in the FC seasonality, focusing on the idea that these changes are linked with baroclinic signals propagating from the ocean interior (Czeschel et al. 2012; Frajka-Williams et al. 2013; Domingues et al. 2016). Analysis of satellite altimetry fields showed that westward-propagating sea height anomaly (SHA) signals within the 73-525-day band demonstrate strong variations on semiannual and annual time scales in the North Atlantic (Polito and Liu 2003), contributing $\sim 42 \%$ of the total SHA variability west of $60^{\circ} \mathrm{W}$ at $27^{\circ} \mathrm{N}$. These signals behave approximately like first-mode baroclinic Rossby waves, and when their amplitudes are large enough and their frequencies are close enough to semiannual/annual, these propagating features can be associated with apparent changes in the FC seasonality (Domingues et al. 2016). The influence of Rossby wave-like baroclinic signals originating in the ocean interior has also previously been noted for longer time-scale changes in the FC (e.g., DiNezio et al. 2009), and Gulf Stream variability (e.g., Sturges et al. 1998).

Several studies based on numerical model simulations have also confirmed that baroclinic signals originating in the ocean interior can modulate the seasonal variability of the currents along the North Atlantic western boundary. For example, one of the earliest efforts was carried out by Boning and Budich (1991) using a $1 / 3^{\circ}$ grid model for the North Atlantic, which showed that the wind-driven annual cycle east of the Bahamas was masked by strong fluctuations with time scales of 100 days, associated with baroclinic signals coming from the interior. Similarly, Czeschel et al. (2012) employed an adjoint model to show that long-wavelength baroclinic Rossby waves coming from the interior can cause a $O(1) \mathrm{Sv}$ adjustment in the FC transport and modify its apparent annual phase. While these model studies have confirmed that baroclinic signals originating in the ocean interior can play an important role in affecting the seasonal variability along the western boundary, they were unable to provide a detailed understanding of the mechanisms controlling the interaction of these signals with the FC. A number of useful insights into these mechanisms have been provided by simplified model studies utilizing highly idealized conditions (Nof 1988; Milliff and McWilliams 1994; Nof 1999; Simmons and Nof 2002; Kanzow et al. 2009). These studies have showed that the boundary response was largely dominated by the development of coastally trapped waves and walljet features. While these assessments based on highly idealized ocean conditions have provided many useful ideas, the mechanisms those studies proposed for linking open ocean signals with changes in the western boundary circulation have not previously be tested and studied under more realistic ocean conditions.

The study presented herein aims to build upon the insights gained in the earlier idealized analyses and to further improve understanding of FC seasonal variability 

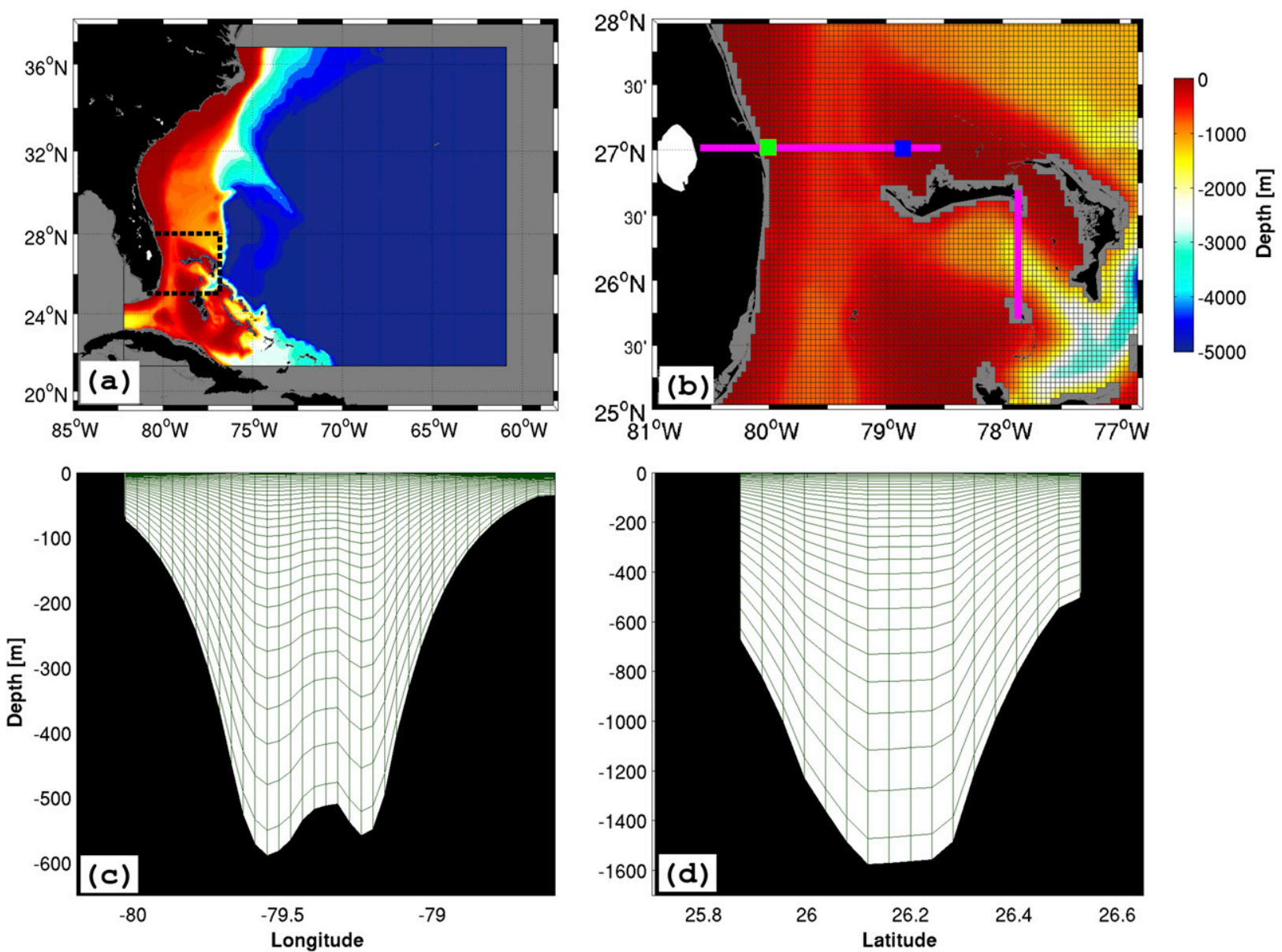

FIG. 1. (a) ROMS domain used to carry out the numerical experiments developed in this study, showing in detail the (b) bathymetry and grid resolution for areas in the proximity of the Florida Straits. Magenta lines in (b) mark the location of vertical sections in the (c) Florida Straits and (d) Northwest Providence Channel. Time series of SHA are retrieved in locations at the coast of Florida (green square) and the Bahamas (blue square).

by testing specific mechanisms linking westwardpropagating signals from the ocean interior to changes in FC transport using realistic numerical experiments. These new experiments have focused on assessing the western boundary response to eddy-like features that are explicitly prescribed in the ocean interior. Two sets of numerical experiments were carried out and are contrasted here to derive an understanding of the key mechanisms. The two experiments will be classified as "with" and "without" a background FC circulation, and the differences in these numerical runs provides complementary information on the mechanisms driving the response at the western boundary. This manuscript is organized as follows: in section 2 , the numerical model used and numerical experiments developed in this study are described; in section 3 , results from the numerical experiments carried out without the background circulation are presented; in section 4 , results from the experiments carried out with the background circulation, including the FC, are addressed; and in section 5, key results obtained in this study are discussed and the main conclusions are presented.

\section{Methods: Model and numerical experiments}

The research results presented in this study are based on numerical experiments using the Regional Ocean Modeling System (ROMS; available at www.myroms.org). ROMS consists of a free-surface, terrain-following ocean model that solves the hydrostatic primitive momentum equations in a staggered Arakawa C-grid (Shchepetkin and McWilliams 2005). Experiments are carried out in a domain bounded by $82^{\circ}-60^{\circ} \mathrm{W}$ and $21^{\circ}-37^{\circ} \mathrm{N}$ (Fig. 1a). The model grid has a horizontal resolution of approximately $1 / 25^{\circ}$, with $540 \times 390$ points in the longitudinal and latitudinal directions, respectively, and 30 vertical 
TABLE 1. Properties of experiments from set SENS-E0x in terms of simulated the eddy diameter and intensity (eddy maximum $\mathrm{SSH}$ ).

\begin{tabular}{lccc}
\hline \hline Exp. name & Diameter $(\mathrm{km})$ & Intensity $(\mathrm{SSH} ; \mathrm{cm})$ & Initial location \\
\hline SENS-E01 & 250 & 7.5 & $27^{\circ} \mathrm{N}, 74^{\circ} \mathrm{W}$ \\
SENS-E02 & 150 & 15 & $27^{\circ} \mathrm{N}, 74^{\circ} \mathrm{W}$ \\
SENS-E03 & 200 & 15 & $27^{\circ} \mathrm{N}, 74^{\circ} \mathrm{W}$ \\
SENS-E04 & 250 & 15 & $27^{\circ} \mathrm{N}, 74^{\circ} \mathrm{W}$ \\
SENS-E05 & 300 & 15 & $27^{\circ} \mathrm{N}, 74^{\circ} \mathrm{W}$ \\
SENS-E06 & 350 & 15 & $27^{\circ} \mathrm{N}, 74^{\circ} \mathrm{W}$ \\
\hline
\end{tabular}

layers. A realistic bottom topography derived from ETOPO-1 (Amante and Eakins 2009) is used for areas in the vicinity of the North Atlantic western boundary, which are the focus of this study. Specific information about the configuration of ROMS and the model domain are provided in appendix A.

To investigate the mechanisms through which eddylike westward-propagating signals can affect the FC variability in the Florida Straits, two different sets of numerical experiments were developed, using controlled conditions in a realistic setup. In the first set of experiments (SENS-E0x), a sensitivity analysis was carried out based on six experiments developed in the absence of the FC and other background flows, to facilitate an initial understanding of the responses generated by westwardpropagating signals reaching the eastern seaboard of North America. For these six experiments, flat-isopycnal conditions were imposed at all grid points by applying the domain-wide average temperature, salinity, and density profiles from the World Ocean Atlas 2013 (Locarnini et al. 2013; Zweng et al. 2013) (Fig. S1 in the online supplemental material). Flat-isopycnal conditions were initially prescribed to ensure stationary initial conditions, removing background baroclinic flows that are intrinsic to real-ocean climatological fields. Single eddy-like features with different diameters $(150-350 \mathrm{~km})$, based on observed eddy scales estimated here from regional altimetry data (appendix A; Fig. S2), were then prescribed east of the Bahamas at $74^{\circ} \mathrm{W}$ for each of the six SENS-E0x experiments (Table 1; Fig. S3). These features were included as perturbations in the depth of the pycnocline of the initial condition fields for each experiment, using a feature model approach (Calado et al. 2008). Additional details about this method can be found in appendix B. Experiments from the set SENS-E0x are then integrated forward for 320 days, providing enough time for the prescribed signals to complete their interaction with the boundary.

A second set of five experiments (EdFC-E0x), which included the background ocean circulation, was then used to evaluate the FC response to signals reaching the western
TABLE 2. Properties of experiments from set EdFC-E0x in terms of simulated eddy diameter and intensity (eddy maximum SSH), and initial location of eddy features.

\begin{tabular}{lccc}
\hline Exp. name & Diameter $(\mathrm{km})$ & Intensity $(\mathrm{SSH} ; \mathrm{cm})$ & Initial location \\
\hline CNTR & - & - & - \\
EdFC-E01 & 250 & 15 & $25.5^{\circ} \mathrm{N}, 74^{\circ} \mathrm{W}$ \\
EdFC-E02 & 250 & 15 & $26.0^{\circ} \mathrm{N}, 74^{\circ} \mathrm{W}$ \\
EdFC-E03 & 250 & 15 & $26.5^{\circ} \mathrm{N}, 74^{\circ} \mathrm{W}$ \\
EdFC-E04 & 250 & 15 & $27.0^{\circ} \mathrm{N}, 74^{\circ} \mathrm{W}$ \\
EdFC-E05 & 250 & 15 & $28.5^{\circ} \mathrm{N}, 75^{\circ} \mathrm{W}$ \\
\hline
\end{tabular}

boundary under more realistic ocean conditions. To accomplish this, experiments from set EdFC-E0x were developed using initial and boundary condition fields derived from averaging a 6-yr data-assimilation run for the North Atlantic Ocean (Kourafalou et al. 2016), with boundary conditions (temperature, salinity, baroclinic and barotropic velocities, and free surface) set to constant values along the boundary. Initial condition fields were then perturbed with single eddy-like westwardpropagating signals using the feature model approach (appendix B). An ensemble of 5 numerical experiments was developed by slightly varying the location where the eddies were started, with the objective of simulating the FC response in the Florida Straits forced by these features (Table 2; Fig. S4). Finally, an additional "control run" experiment (CNTR) was completed using the same unperturbed initial conditions and model configuration from the EdFC-E0x experiments, but with no eddy-like mesoscale features prescribed. Comparisons between outputs from the eddy experiments (EdFC-E0x) and the control run (CNTR) were then employed to gain insight into the mechanisms linking open ocean signals with the response at the western boundary. Experiments from this set were run for 500 days.

All of the experiments described above were run in the absence of wind forcing, in order to isolate the FC response driven solely by the prescribed westwardpropagating eddy-like signals. For additional information about the model configurations, the reader is referred to appendix A.

\section{No FC case study: Eddy-wall interactions}

The resulting circulation patterns from experiments SENS-E0x are initially characterized by an open ocean phase that is dominated by the westward propagation of the prescribed eddy-like signals. The typical behavior of the eddies is illustrated in Fig. 2a, taken from experiment SENS-E04 where an anticyclonic eddy of 250-km diameter was initially prescribed at $74^{\circ} \mathrm{W}$. The longitudetime Hovmöller diagram of sea surface height (SSH) along 

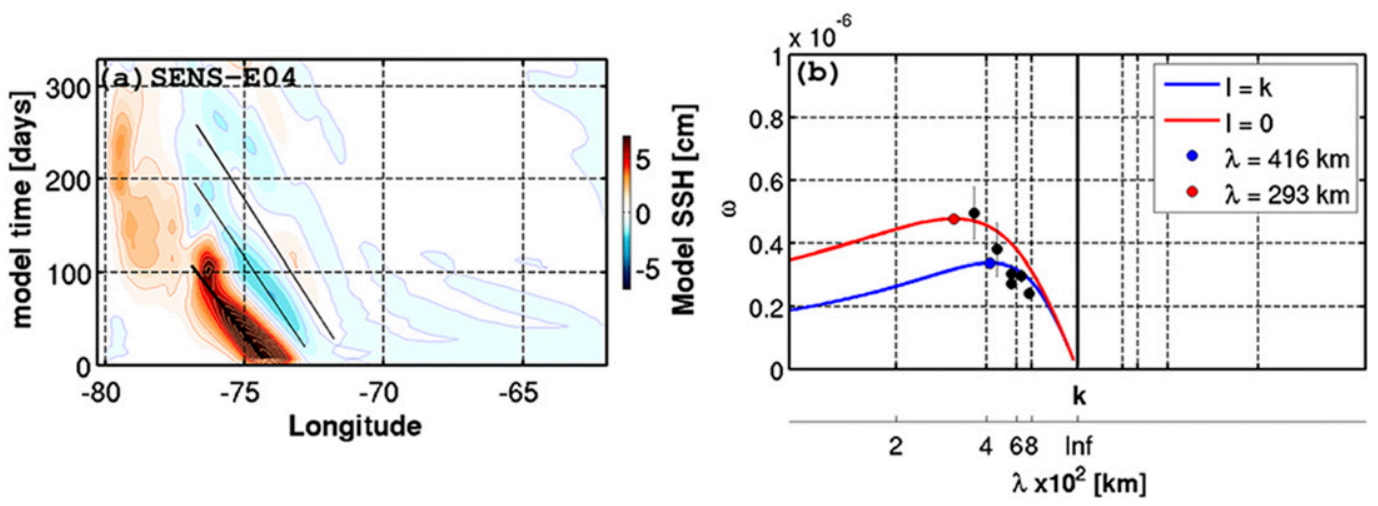

FIG. 2. (a) Longitude-time Hovmöller diagram of SHA along $27^{\circ} \mathrm{N}$ for experiment SENS-E04. (b) Dispersion relationship for first-mode baroclinic Rossby waves setting the deformation radius to $47 \mathrm{~km}$ at $27^{\circ} \mathrm{N}$, using isotropic zonal and meridional wavenumbers $(k=1$, blue line), and also setting the meridional wavenumber to zero $(l=0$, red line). The black dots in (b) indicate the dispersion of SHA signals at $27^{\circ} \mathrm{N}$ for individual experiments from set SENS-E0x.

$27^{\circ} \mathrm{N}$ indicates that the eddy propagates westward with a phase speed of $-2.30 \pm 0.22 \mathrm{~km} \mathrm{day}^{-1}$. As the prescribed eddy-like signal propagates westward, the development of a Rossby wave field in the wake of the eddy is noticeable (Fig. 2a), which is consistent with results from previous studies based on simplified ocean conditions (Milliff and McWilliams 1994). Analysis of all of the SENS-E0x experiments shows that prescribed eddylike signals propagated at an average rate of $-2.36 \pm$ $0.18 \mathrm{~km} \mathrm{day}^{-1}$ (not shown), which is generally consistent with the values expected from classical Rossby wave theory (Fig. 2b).

The prescribed eddy-like features reach the western boundary region at $\sim 26.5^{\circ} \mathrm{N}$ east of the Bahamas archipelago after $\sim 70$ days of simulation (Fig. 3a). Analysis of individual snapshots of the resulting surface velocity field shows that, as the eddy reaches the continental slope east of the Bahamas, it remains in an approximate fixed location as its volume is slowly drained along the topography. As this process takes place, a jet-like feature resembling a wall jet (Nof 1999) is observed to propagate through Northwest Providence Channel (Fig. 3b), reaching the Florida Straits after 119 days of simulation. As the eddy loses volume along the boundary, its diameter and magnitude become progressively smaller, taking approximately 200 days for all of the eddy volume to be drained (Fig. 3c). Wall jets often shed smaller eddy-like features within Northwest Providence Channel (Fig. 3c). The evolution of other SENS-E0x experiments is in good agreement with the results from experiment SENS-E04.

To assess the overall variability forced by the prescribed westward-propagating eddy-like signals, the total meridional volume transport integrated across the Florida Straits at $27^{\circ} \mathrm{N}$ is quantified here and used as an indicator. Time series of volume transport in the Florida Straits (Fig. 4a) show anomalies reaching values of 1) $\sim 1 \mathrm{~Sv}$ for experiments SENS-E02 to SENS-E06, which were initialized with anticyclonic eddies having $\mathrm{SSH}$ amplitudes of $15 \mathrm{~cm}$ and diameters ranging between 150 and $350 \mathrm{~km}$ (Table 1), and 2) $0.5 \mathrm{~Sv}$ for experiment SENS-E01, which was initialized with an anticyclonic eddy with $7.5-\mathrm{cm} \mathrm{SSH}$ amplitude and diameter of $250 \mathrm{~km}$ (Table 1). For all experiments, the peak volume transport in the Florida Straits is observed around day 119 (Fig. 4a), coinciding with the timing when the wall-jet features first reach the Florida Straits (Fig. 3b). Interestingly, however, the transport anomalies in the Florida Straits start building up around day 50, before the wall-jet feature develops. At day 70 (Fig. 5a), broad SHA signals are observed on the eastern side of the Florida Straits (Fig. 5b). These SHA signals are linked with northward velocity anomalies of $\sim 1 \mathrm{~cm} \mathrm{~s}^{-1}$ that occupy most of the water column in the Florida Straits (Fig. 5c), indicating a barotropic response. These results show that prescribed eddies generate a band-limited range of Rossby wavenumbers, some of which can actually propagate faster than the eddy, causing the first stage of the forced response in the absence of background flows. In the second stage, developed wall-jet features propagate toward the Florida Straits, causing a more baroclinic response (Figs. 5e,f) during the peak transport at day 119.

The results from the SENS-E0x experiments also suggest that the response in the Florida Straits is possibly sensitive to the intensity of features interacting directly with the boundary, but not to their diameters. For example, while experiment SENS-E01, which was developed with a $7.5-\mathrm{cm} \mathrm{SSH}$ anomaly and diameter of $250 \mathrm{~km}$, caused a response of $\sim 0.5 \mathrm{~Sv}$, the remaining experiments with different eddy diameters and $15-\mathrm{cm} \mathrm{SSH}$ anomaly all forced 

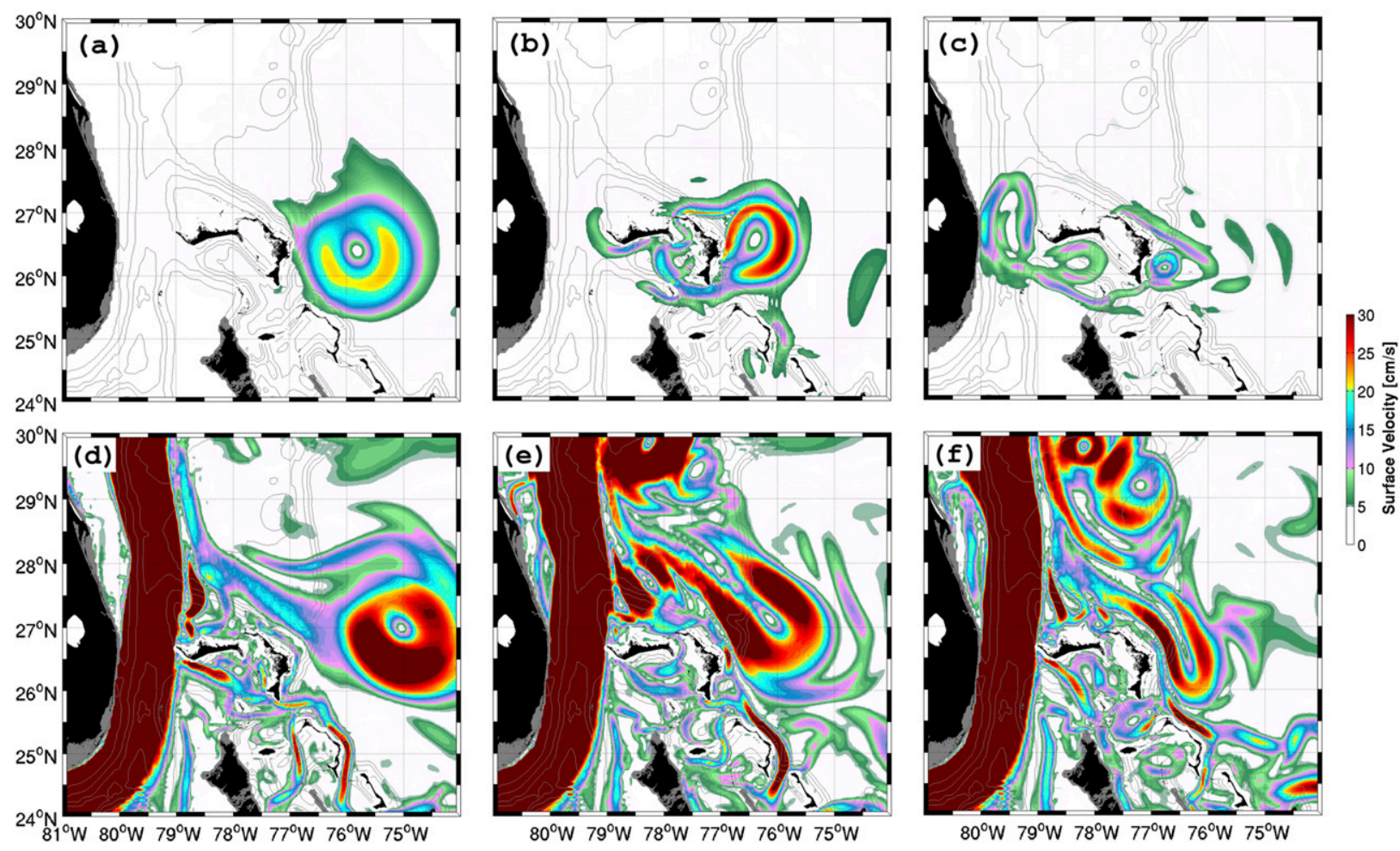

FIG. 3. Surface velocity magnitude fields for experiment SENS-E04 at days (a) 70, (b) 119, and (c) 201, and for experiment EdFC-E04 at days (d) 21, (e) 63, and (f) 105 . Black contours indicate bottom topography with contours every $200 \mathrm{~m}$ for areas shallower than $1000 \mathrm{~m}$ close to the coast and every $1000 \mathrm{~m}$ for deeper open ocean areas; solid black indicates land.

similar responses reaching values of $\sim 1 \mathrm{~Sv}$. The results show that the time scale of the forced response in the Straits is also not as sensitive to varying eddy diameters ranging between 150 and $350 \mathrm{~km}$. The key finding from experiments SENS-E0x is that the development of a broad Rossby wave field (including barotropic and baroclinic components) and wall-jet features are the main mechanism for linking open ocean eddy signals with the response in the Florida Straits in the absence of background flows.

\section{With FC case study: Eddy-background flow interactions}

Before proceeding with the analysis of forced FC experiments that included prescribed eddy-like features (EdFC-E0x), an assessment of the background levels of variability associated with the control run experiment (CNTR) is presented. This analysis was carried out because this study employed a realistic nonlinear ocean model that simulates the FC and Gulf Stream, and which therefore permits the development of instabilities (e.g., Lee and Csanady 1994) and energetic meandering (e.g., Johns and Watts 1986; Rossby et al. 2010). An assessment of the inherent background levels of variability in experiment CNTR is crucial for later understanding of the forced experiments EdFC-E0x.

\section{a. The control run experiment}

Experiment CNTR includes a realistic representation of the North Atlantic western boundary circulation, with a mean FC that is characterized by a well-defined jet flowing along the topographic slope in the Florida Straits at $27^{\circ} \mathrm{N}$ (Fig. 6a), which agrees well with the long-term average velocity structure observed previously (e.g., see Fig. 6 of Meinen and Luther 2016). The CNTR run also shows a mean northward flowing Antilles Current characterized by a subsurface maximum (Fig. S5b), consistent with what has been observed in the real ocean (e.g., Rosenfeld et al. 1989; Lee et al. 1990). The simulated FC carries a total volume transport of $29.5 \pm 0.6 \mathrm{~Sv}$, which is slightly smaller than the average values of $\sim 32 \mathrm{~Sv}$ reported based on in situ observations (e.g., Leaman et al. 1987; Baringer and Larsen 2001; Beal et al. 2008; Meinen et al. 2010). The slightly reduced FC transport obtained in experiment CNTR is consistent with results simulated by the data-assimilation run for the North Atlantic Ocean (Kourafalou et al. 2016), which is used as fixed boundary conditions in our experiments. The slightly reduced FC volume transport, however, is not expected to affect the 


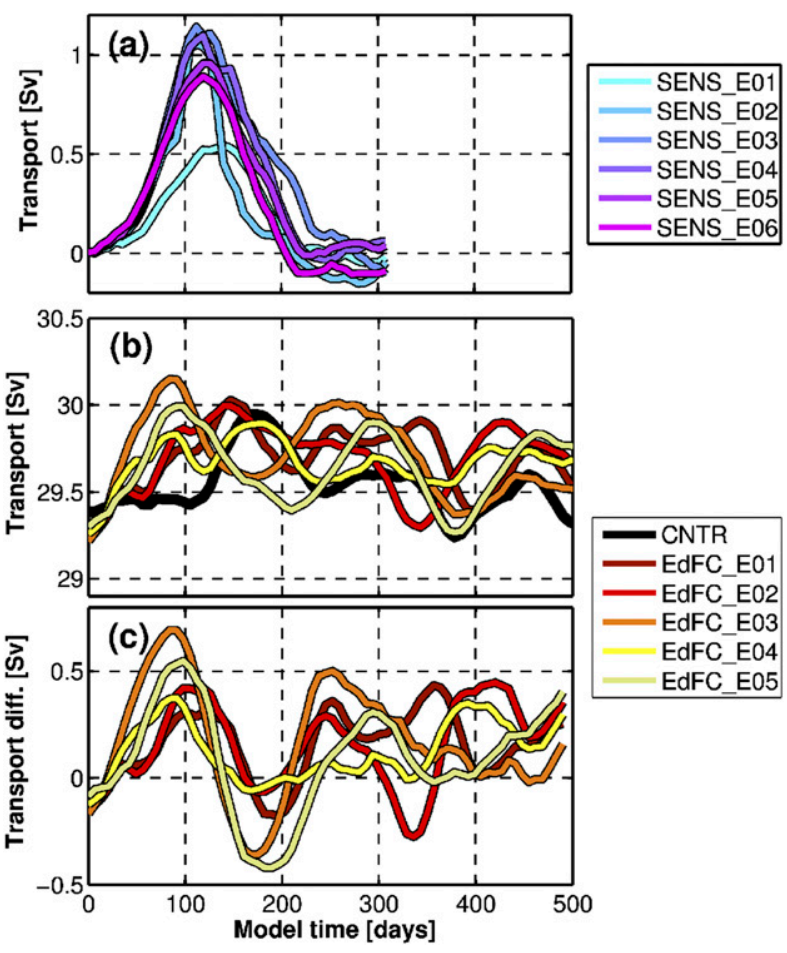

FIG. 4. Time series of meridional volume transport at $27^{\circ} \mathrm{N}$ in the Florida Straits (magenta line; Fig. 1b) for individual experiments from sets (a) SENS-E0x and (b) EdFC-E0x. The black line in (b) shows the FC volume transport from the control run experiment CNTR. (c) Time series of FC volume transport differences between results from experiments EdFC-E0x and the control run CNTR.

findings of this study. Analysis of the FC transport time series from experiment CNTR indicates that about $25 \%$ of the variance in the model is linked with variability within the frequency band that is the focus of this study [73-525-day periods, standard deviation $(\mathrm{STD})=0.2 \mathrm{~Sv}$, while the remaining variability is dominated by higher frequencies (shorter periods). The filtered time series of FC transport for periods within the 73-525-day band (black line, Fig. 4b) shows changes in the transport of $<1$ Sv. A detailed assessment of the mechanisms causing this internal variability in the control run is required before undertaking the additional complexity of the prescribed eddy-like westward-propagating signals and understanding how they can modulate the FC variability.

Analysis of meridional velocity in the Florida Straits shows that most of the variability in the model flows is observed over the continental slope on the western side of the Straits (Fig. 6b). These results are consistent with findings based on real ocean observations (e.g., Leaman and Molinari 1987; Leaman et al. 1987; Beal et al. 2008). This variability is generally attributed to lateral meandering of the FC jet and/or to coastally trapped waves (e.g., Mooers et al. 2005). The dynamics associated with flow along the U.S. East Coast imply that coastally trapped signals must propagate southward along the coastal waveguide. Latitude-time Hovmöller diagrams of SHA along the coastal waveguide (Fig. 7a) confirm that the observed variability in experiment CNTR (Fig. 7b) is strongly associated with southward propagating signals. Analysis of implied slopes shows that signals propagate southward at a rate of $-87.1 \pm 30.2 \mathrm{~km} \mathrm{day}^{-1}$, which is compatible with the rate observed for first-mode coastally trapped waves along the northeast coast of the United States (Elipot et al. 2013). This analysis also indicates that dominant signals are mostly generated in the model at $\sim 36^{\circ} \mathrm{N}$, in the proximity of Cape Hatteras, and take approximately 20 days to reach the Florida Straits. Secondary signals are also observed to develop midway between Cape Hatteras and $27^{\circ} \mathrm{N}$. For instance, positive SHA anomalies observed in the Florida Straits between days 250 and 300 (magenta square, Fig. 7b) can be traced to $\sim 29^{\circ} \mathrm{N}$.

While coastally trapped signals appear to provide a key source of variability for experiment CNTR, Gulf Stream meandering is also a significant process in the control run downstream of the Florida Straits. Fields of surface velocity (Fig. 8) show that intense Gulf Stream meandering occurs between $28^{\circ}$ and $35^{\circ} \mathrm{N}$. Because all of the simulations were developed in this study in the absence of wind forcing, the generation of coastally trapped signals is only possible through shelf interactions with offshore features. Gulf Stream meandering appears to be the main source triggering the generation of coastally trapped signals and coastal SHA variability described above for experiment CNTR. In fact, detailed inspection of SHA snapshots confirms that northward propagating anomalies associated with Gulf Stream meanders can interact with the sloping topography, and trigger the southward propagating coastally trapped signals (Fig. S6). Furthermore, the interaction of Gulf Stream meanders with topographic features along the southeast U.S. coast, such as the Charleston Bump $\left(\sim 32^{\circ} \mathrm{N}\right)$, has previously been identified as a key source for southward propagating coastally trapped signals (e.g., Oey et al. 1992). In addition, results obtained here also show that Gulf Stream meandering can be associated with the shedding of cyclonic and anticyclonic eddies in the region between the Florida Straits and Cape Hatteras (Figs. 8b,c), which are often reabsorbed by the current later on (Fig. 8d). Therefore, both meandering and generation of coastally trapped waves are prominent processes associated with the intrinsic variability in the control run experiment CNTR.

\section{b. Perturbed experiments EdFC-EOx}

Experiments from set EdFC-E0x were initialized with both the mean circulation (similar to CNTR) and 

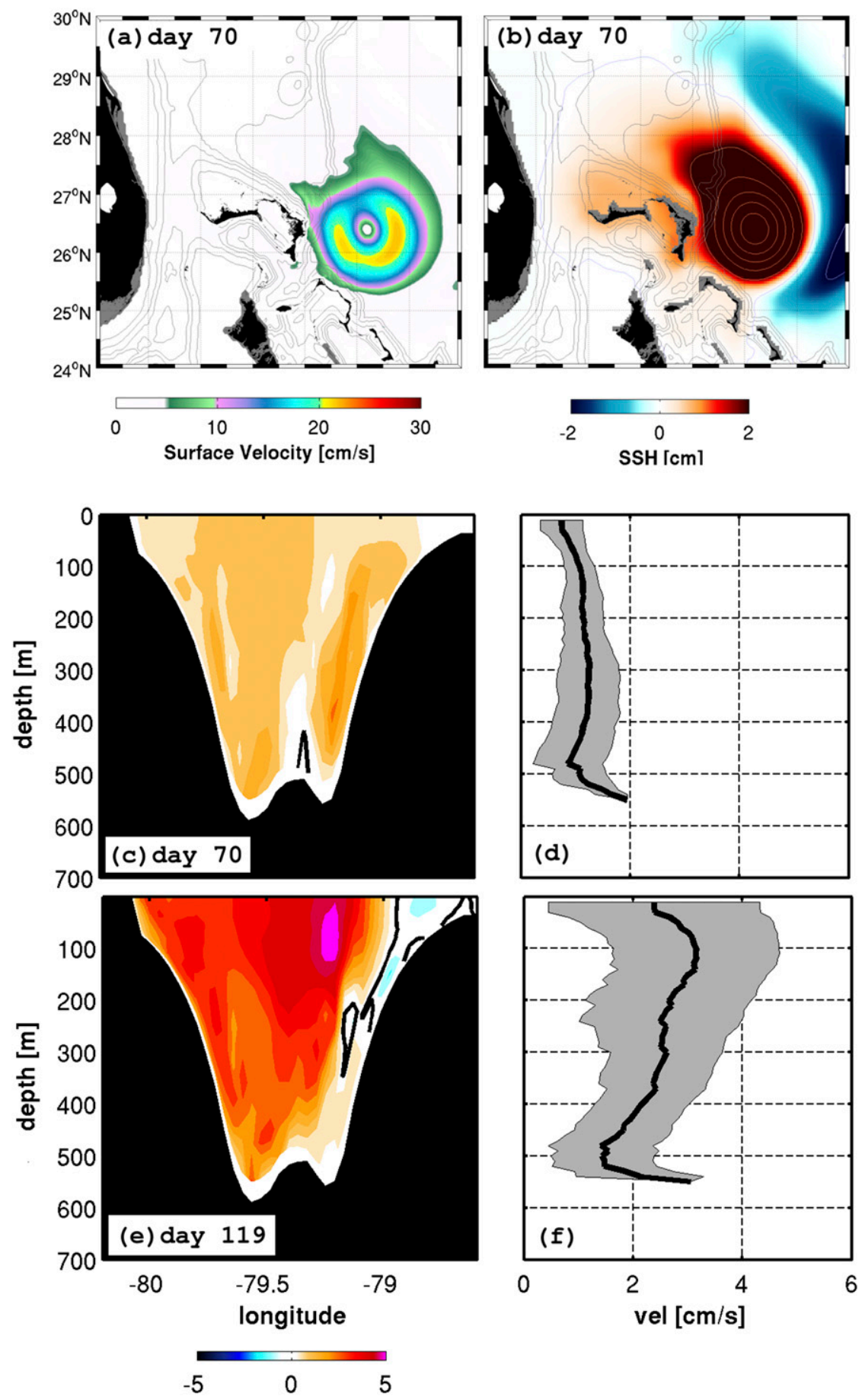

\section{Meridional Velocity $\left[\mathrm{cm} \mathrm{s}^{-1}\right.$ ]}

FIG. 5. Snapshots of (a) surface velocity magnitude and of (b) SHA at day 70 of the model run for experiment SENS-E04. (c) Meridional velocity section and (d) averaged meridional velocity across the Florida Straits at day 70 for experiment SENS-E04. (e) Meridional velocity section and (f) averaged meridional velocity across the Florida Straits at day 119 for experiment SENS-E04. Gray shading in (d) and (f) shows the standard deviation of meridional velocities across the Florida Straits. 

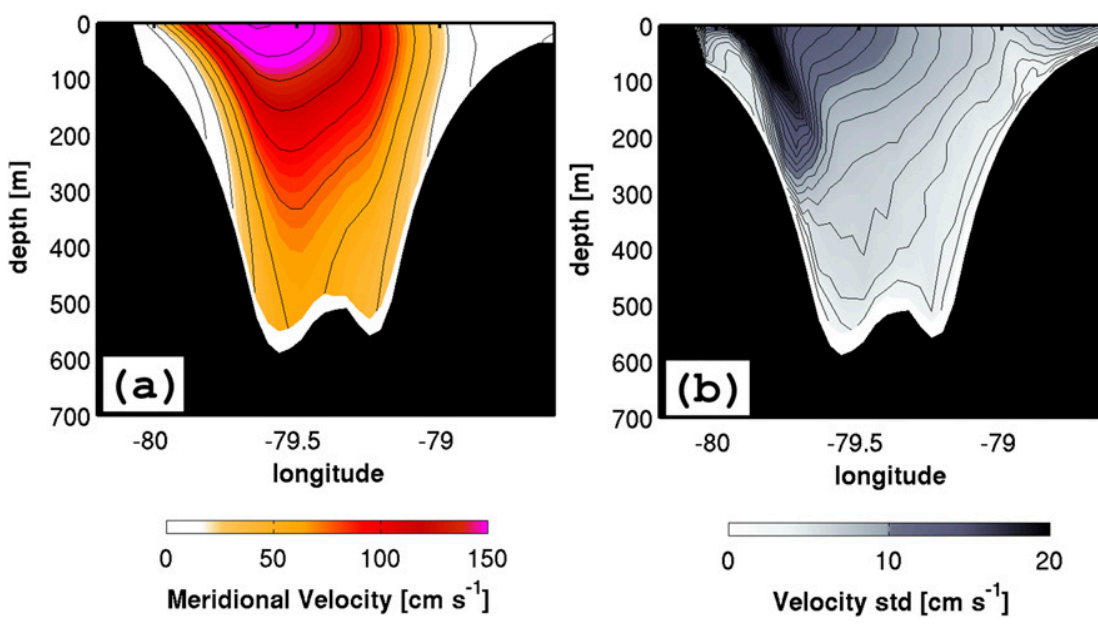

FIG. 6. (a) Time-mean meridional velocity and (b) standard deviation in the Florida Straits for the control run experiment CNTR. Filled black areas represent land.

eddy-like features prescribed in the ocean interior east of the Bahamas. Time series of FC volume transport (Fig. 4b) show that the FC flow in experiments EdFCE0x remained consistent with CNTR in terms of mean and overall variability $(29.7 \pm 0.2 \mathrm{~Sv})$. Therefore, the inclusion of westward-propagating eddies did not impact the overall amplitude of the FC variability in these experiments, which remained comparable to experiment CNTR. However, one of the key results obtained is that the FC transport from experiments EdFC-E0x diverges from CNTR in terms of timing and phase. Phase discrepancies are more readily identified by analyzing the difference in the FC transport between experiments EdFC-E0x and the control run (Fig. 4c). For all EdFC-0x experiments, phase discrepancies result in differences with amplitude of $\sim 1 \mathrm{~Sv}$, with the largest differences observed around day 100. Analysis of individual FC transport time series indicates that the eddy-forced experiments develop peak transport values earlier than the control run CNTR (Fig. 4b). Following the first 100 days of simulation, all EdFC-E0x experiments behave independently, showing increased values of ensemble variability.

Surface velocity fields from experiments EdFC-E0x indicate that prescribed eddy-like features in the experiments with the background FC circulation behave remarkably differently from those in the equivalent experiments without the background circulation. In the EdFC-E0x experiments, the model solution is marked by substantial interaction between the prescribed eddy and the background circulation. For example, in experiment EdFC-E04, the prescribed anticyclonic eddy is mostly drained northward by the Antilles Current east of the Bahamas (Figs. 3d,e), while in experiment
SENS-E04 the anticyclone interacts directly with the sloping topography and is drained through Northwest Providence Channel (Figs. 3b,c). All EdFC-E0x experiments are consistent with the behavior displayed in experiment EdFC-E04.

Further analysis of SHA snapshots for experiment EdFC-E04 (Fig. 9) indicates that, as the prescribed eddy interacts with the background circulation, SHA signals associated with the eddy are mostly observed to propagate northward (green line, Fig. 9) with the dominant circulation, that is, the Antilles Current and Gulf Stream. The SHA signals from the anticyclone subsequently start to merge and interact with the Gulf Stream downstream of the Florida Straits (days 84-133, Fig. 9), and these SHA signals then propagate northward toward Cape Hatteras (133-154 days, Fig. 9). Even though SHA signals are mostly observed to propagate northward, a closer inspection of the SHA fields reveals that broad and less intense SHA signals associated with the eddy can quickly propagate through the Bahamas archipelago (day 63, magenta ellipse, Fig. 9). These signals reach the Florida Straits around day 63, and indicate a partially direct interaction with the FC. The broad and less intense SHA signals observed here are similar to the Rossby wave field excited by the eddy in experiment SENS-E04 developed without the background circulation (Fig. 5b). At this stage, the smaller response observed in experiment EdFC-04 is likely because the later draining of the prescribed eddy through Northwest Providence Channel observed in experiment SENS-04 is not observed here. In the EdFC-E0x experiments, drainage of prescribed eddies is largely diverted north of the Straits by the Antilles Current. 

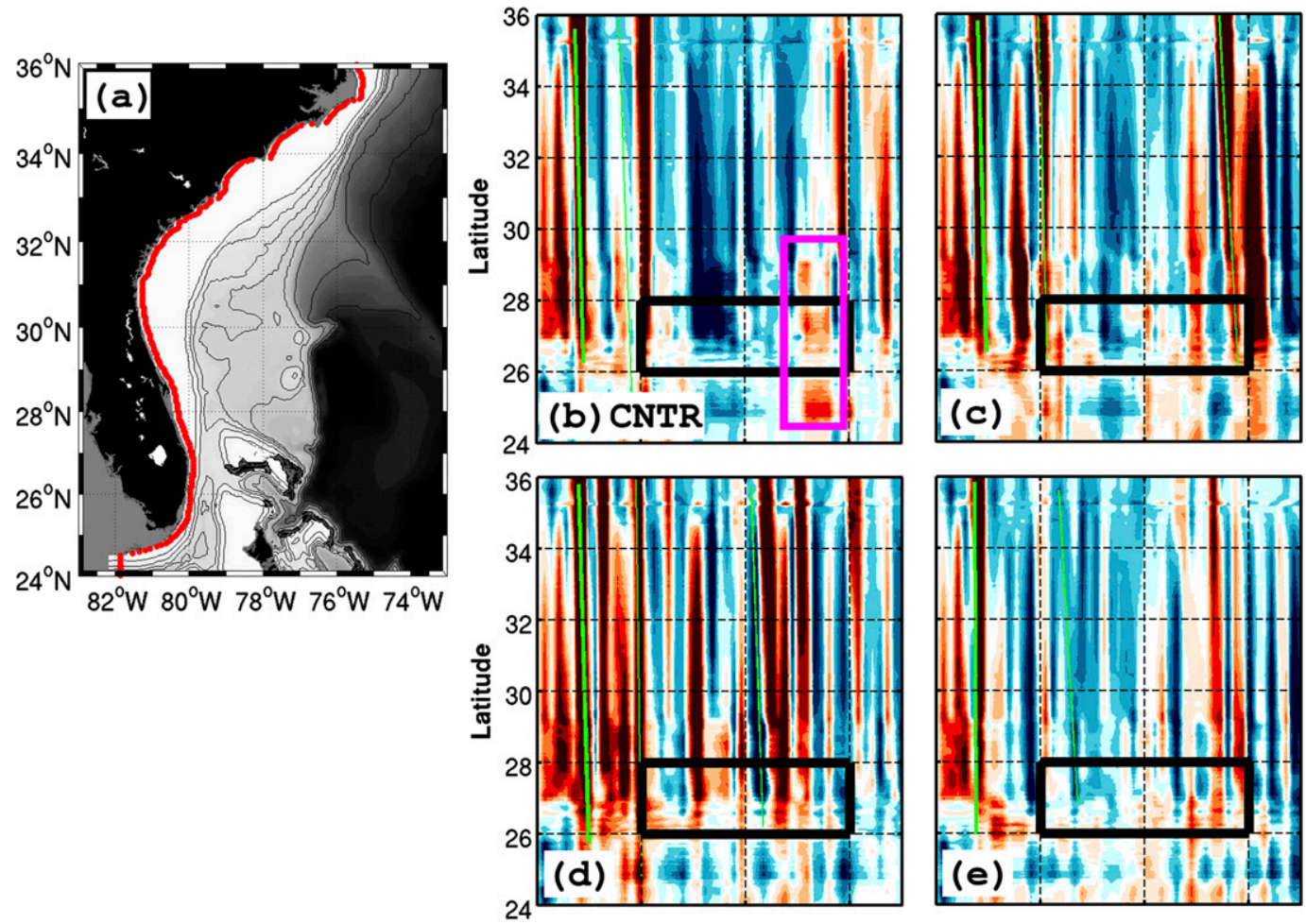

FIG. 7. (a) Locations along the east coast of the United States where time series of SHA are retrieved for experiments CNTR and EdFC-E0x (red dots). Latitude-time Hovmöller diagram of coastal SHA for experiments (b) CNTR, (c) EdFC-E01, (d) EdFC-E02, (e) EdFC-E03, (f) EdFC-E04, and (g) EdFC-E05.

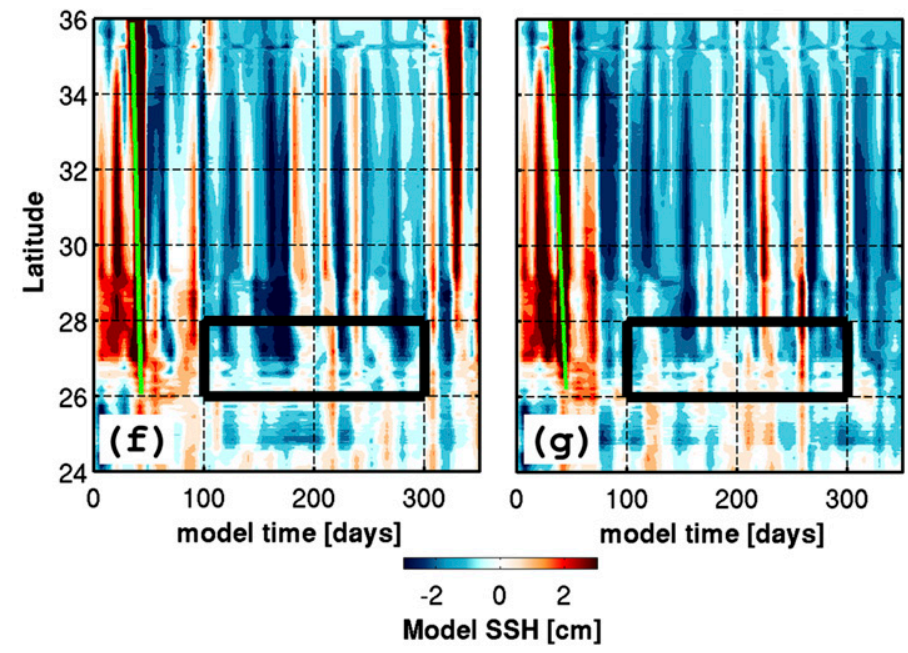

As the eddies in experiments EdFC-E0x begin to interact with the western boundary, changes in the Gulf Stream meandering may occur as a result of nonlinear dynamics. To verify this, the meandering variability from EdFC-E0x experiments is evaluated and compared with the control run. Time series of Gulf Stream location are computed at $28^{\circ}, 30^{\circ}, 32^{\circ}$, and $34^{\circ} \mathrm{N}$ by following the maximum jet intensity as a function of longitude (Fig. 10). This analysis shows that at $28^{\circ} \mathrm{N}$ the ensemble meandering variability observed in experiments EdFCE0x diverges from the control run around day 50, while north of $28^{\circ} \mathrm{N}$ changes in meandering are observed progressively later in time. At all latitudes, the ensemble meandering behavior recorded in EdFC-E0x experiments shows the largest discrepancies with respect to the control run after day 200, suggesting that the different experiments developed an independent behavior with time. These results show that the introduction of eddy-like features in the ocean interior causes changes in the Gulf Stream meandering.

Time series of coastal SHA (Figs. 7c-g) for these experiments exhibit the signature of coastally trapped waves similar to what was observed in the control run CNTR (Fig. 7b). Previous analysis of the control 

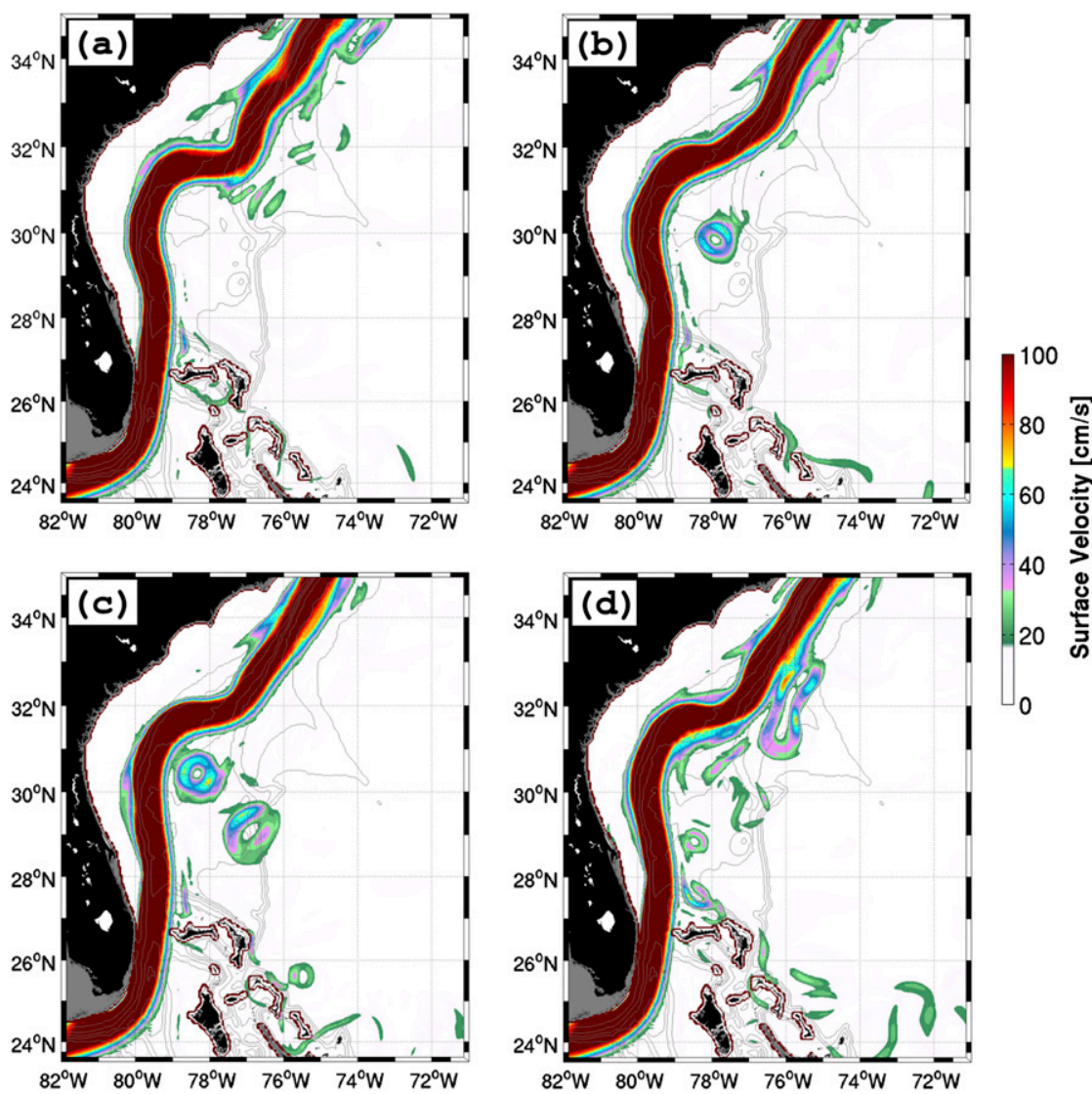

FIG. 8. Snapshots of surface velocity magnitude for experiment CNTR at days (a) 35, (b) 112,

(c) 147, (d) 203 .

experiment CNTR showed that Gulf Stream meandering generates coastally trapped signals that are ultimately transmitted to the Florida Straits. Therefore, the observed changes in the Gulf Stream meandering in experiments EdFC-E0x are likely the cause of changes in coastal SHA variability for these experiments compared to the control run. For example, between days 100 and 300, coastal SHA variability in the control run CNTR at $27^{\circ} \mathrm{N}$ (black square, Fig. $7 \mathrm{~b}$ ) is remarkably distinct from the coastal variability exhibited by other EdFC-E0x experiments (black square, Figs. 7c-g).

To provide a more quantitative assessment of the mechanisms linking changes in the coastal SHA variability with the modulation of the FC transport variability, a multilinear regression approach is employed as follows 1) time series of coastal SHA differences with respect to experiment CNTR were retrieved from both sides of the Florida Straits at $27^{\circ} \mathrm{N}$ (squares, Fig. 1b) as indicators of changes in the coastal SHA variability; 2) time series of SHA and of FC transport differences with respect to CNTR were normalized by subtracting the mean and dividing by the standard deviation; and
3) a multilinear regression analysis (formula below) was employed using a bootstrap approach (Johnson 2001), in which the normalized time series of SHA differences were used as predictors ( $\mathbf{X}$ matrix) for changes in the FC transport (Y vector). The multilinear regression analysis consists of solving

$$
\begin{aligned}
& {\left[\begin{array}{c}
A_{\mathrm{FL}} \\
A_{\mathrm{BHS}}
\end{array}\right]=}\left(\mathbf{X}^{\mathrm{T}} \times \mathbf{X}\right)^{-1} \times \mathbf{X}^{\mathrm{T}} \times \mathbf{Y}, \\
& \text { with } \mathbf{X}=\left[\begin{array}{cc}
\mathrm{SHA}_{\mathrm{FL}_{t=1}} & \mathrm{SHA}_{\mathrm{BHS}_{t=1}} \\
\vdots & \vdots \\
\mathrm{SHA}_{\mathrm{FL}_{t=n}} & \mathrm{SHA}_{\mathrm{BHS}_{t=n}}
\end{array}\right] \text { and } \\
& \mathbf{Y}=\left[\begin{array}{c}
\mathrm{FC}_{t=1} \\
\vdots \\
\mathrm{FC}_{t=n}
\end{array}\right] .
\end{aligned}
$$

Step 3 was applied using the normalized time series, and also using the actual SHA and transport time series, 

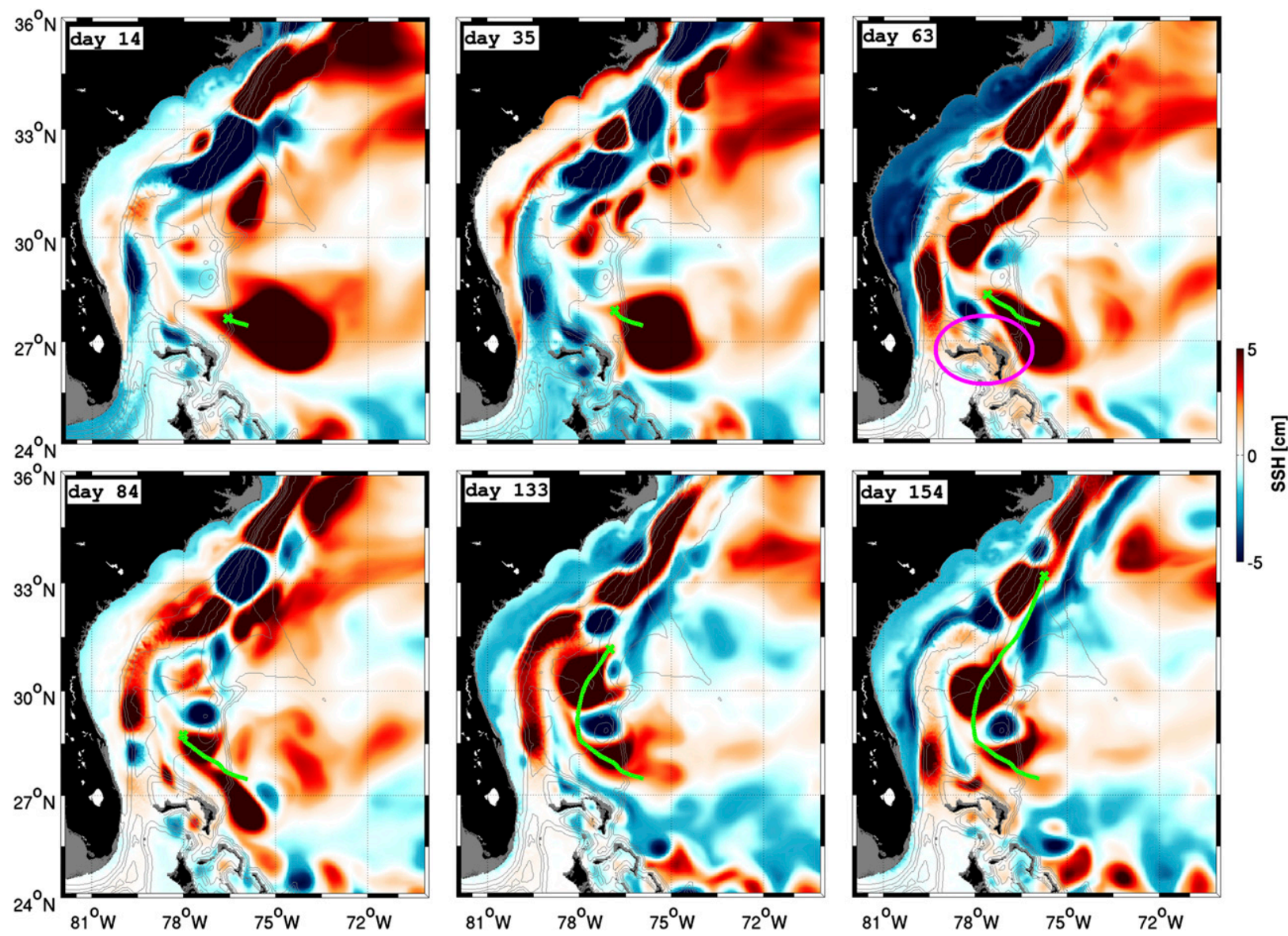

FIG. 9. Fields of SHA from experiment EdFC-E04 at different snapshots of model solution. The green lines indicate the track followed by traceable SHA signals linked with the original anticyclonic eddy prescribed in this experiment. The " $x$ " marker provides an approximate position of the leading edge of the anomaly at each time step traced using visual inspection.

resulting in two sets of slope coefficients $\left(A_{\mathrm{FL}}\right.$ and $\left.A_{\mathrm{BHS}}\right)$ : one set of normalized coefficients, and one set with physical units of Sverdrups per centimeter (Table 3). The correlation coefficient $R_{\mathrm{FC}}$ from the multilinear regression analysis is also shown in Table 3. This approach allows us to more quantitatively assess the influence of changes in the coastal SHA variability for explaining changes in the $\mathrm{FC}$ variability with respect to the control run. Results from this analysis show that time series of coastal SHA differences sampled from the control run experiment CNTR can explain about $46 \%$ (average $R_{\mathrm{FC}}=0.68 \pm 0.08$, Table 3 ) of the simulated volume transport variability across the Florida Straits in this experiment for time scales longer than 73 days. A smaller fraction of about $27 \%$ of the FC variance is accounted for by coastal SHA time series in the Florida Straits under real ocean conditions where wind and other effects also play a role (e.g., Domingues et al. 2016). Slope coefficients estimated for the west side of the Florida Straits $\left(A_{\mathrm{FL}}=-0.57 \pm 0.05\right.$, Table 3$)$ are at least $50 \%$ larger compared to the coefficients from the east side of the Straits in the Bahamas $\left(A_{\mathrm{BHS}}=0.37 \pm 0.03\right)$. In other words, time series of SHA differences along the East Coast of the United States play a more important role in accounting for changes in the FC variability than SHA time series from the Bahamas. Therefore, FC transport differences between EdFC-E0x experiments and the control run CNTR are dominated by the changes in the SHA variability along the coastal waveguide described above. These results show that the introduction of eddy-like signals in the ocean interior can ultimately modulate the FC variability through changes in the variability along the coastal waveguide.

\section{Discussion}

The numerical experiments developed in this study provide insight about the FC variability forced in the Florida Straits by eddy-like westward-propagating signals originating in the interior North Atlantic. 

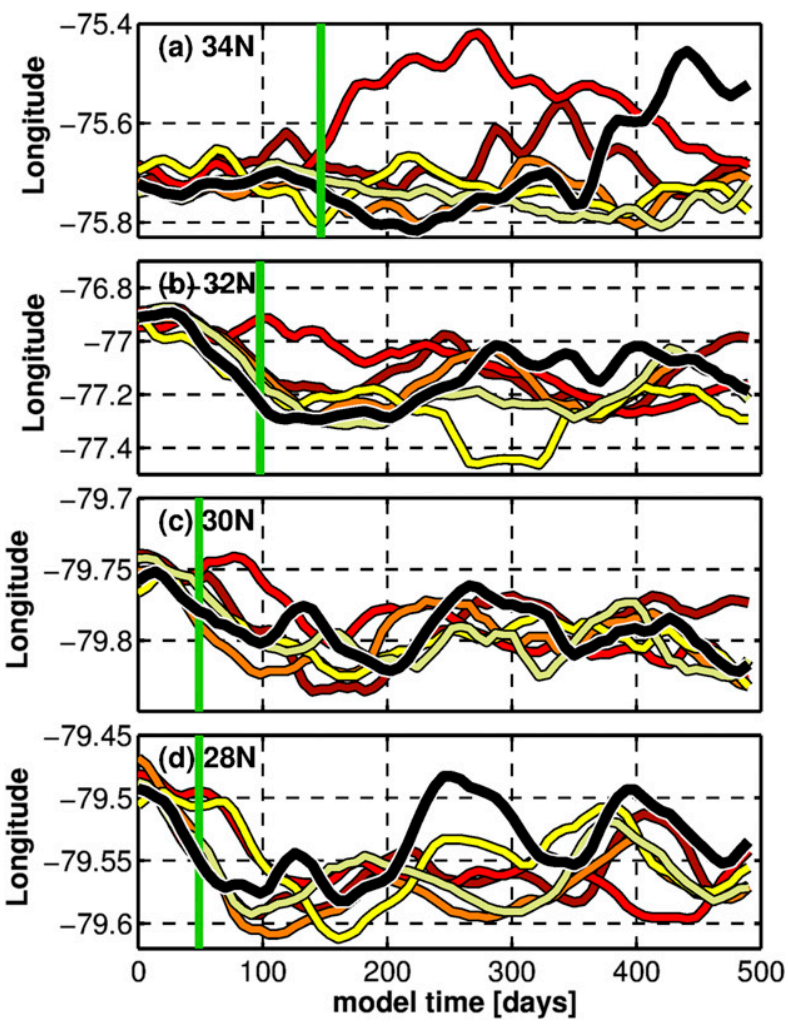

FIG. 10. Time series of Gulf Stream location at (a) $34^{\circ} \mathrm{N}$, (b) $32^{\circ} \mathrm{N}$, (c) $30^{\circ} \mathrm{N}$, and (d) $28^{\circ} \mathrm{N}$ for the different EdFC-E0x experiments, in comparison with the control run experiment CNTR. Lines are color coded according to the legend shown in Fig. 4. The green vertical lines indicate the time when the Gulf Stream meandering ensemble variability doubles with respect to initial values during the first 30 days of the model run.

The analysis reveals that the mechanism driving the response in the Florida Straits in experiments with no background flow (SENS-E0x) differed from the overall mechanism driving changes in the $\mathrm{FC}$ in experiments with realistic background flow (EdFC-E0x). In the absence of background flow, a direct response to forced signals was observed in the Florida Straits characterized by 1) the influence of broad barotropic Rossby wave anomalies in a first stage and 2) the development of wall-jet features in a second stage. Because of this direct relationship between prescribed signals and response in the Florida Straits, we define this as the "direct response mechanism" (Fig. 11a).

The development of the wall jets is associated with the volume of the eddy that leaks along the boundary (Nof 1988, 1999), or along topographic contours off the Bahamas and into the Florida Straits in the case of this study. The rate at which the eddy moves into the wall is controlled by the "peeling rate," which sets the time scale for draining the eddy along the wall. Under the more realistic conditions employed in this study, the leaking
TABLE 3. Results from the multilinear regression analysis performed on the control run and experiments from set EdFC-E0x. Regression slope coefficients $A_{\text {xx }}$ labeled with the subscript "FL" indicate coefficients from the west or Florida side of the Straits, while coefficients labeled with the subscript "BHS" indicate coefficients from the east or Bahamas side of the Straits. The standard deviation (STD) of SHA $(\mathrm{cm})$ for each side of the Florida Straits is shown in the first two columns. Physical coefficients have units of Sverdrups per centimeter, while normalized coefficients are nondimensional. Asterisks indicate values that are not significant at the $95 \%$ confidence level.

\begin{tabular}{|c|c|c|c|c|c|c|c|}
\hline \multirow[b]{2}{*}{ Exp. name } & \multirow{2}{*}{$\begin{array}{c}\text { STD } \\
\text { FL }\end{array}$} & \multirow{2}{*}{$\begin{array}{l}\text { STD } \\
\text { BHS }\end{array}$} & \multicolumn{2}{|c|}{ Physical } & \multicolumn{2}{|c|}{ Normalized } & \multirow[b]{2}{*}{$R_{\mathrm{FC}}$} \\
\hline & & & $A_{\mathrm{FL}}$ & $A_{\mathrm{BHS}}$ & $A_{\mathrm{FL}}$ & $A_{\mathrm{BHS}}$ & \\
\hline $\mathrm{EdF}$ & 2.4 & 0.6 & -0.22 & 0.36 & -0.66 & 0.34 & 0.7 \\
\hline EdFC-E02 & 2.8 & 0.7 & -0.15 & $0.38 *$ & -0.55 & $0.35^{*}$ & 0. \\
\hline EdFC-E03 & 2.3 & 0.7 & -0.20 & 0.44 & -0.56 & 0.37 & 0.6 \\
\hline EdFC-E04 & 2.2 & 0.7 & -0.18 & 0.44 & -0.55 & 0.41 & 0.7 \\
\hline EdFC-E05 & 2.3 & 0.7 & -0.15 & 0.36 & -0.54 & 0.37 & 0.65 \\
\hline
\end{tabular}

process was largely constrained by the gap at the entrance of Northwest Providence Channel, taking approximately 200 days for the entire eddy to leak through the channel. The Northwest Providence Channel corresponds to the main passage connecting the Florida Straits with the western boundary region east of the Bahamas, where strong variability at seasonal time scales is generally observed (e.g., Lee et al. 1990, 1996; Bryden et al. 2005; Johns et al. 2008). Previous studies (Leaman and Molinari 1987; Leaman et al. 1987) also showed that observed variability at seasonal time scales in the Florida Straits was partially associated with intermittent signals coming from the Northwest Providence Channel, which can be associated with the mechanisms described here. Further, using satellitealtimetry observations, Frajka-Williams et al. (2013) reported the development of similar wall-jet features linked with anticyclonic eddies originating east of the Bahamas, which were found to cause changes in the FC transport on time scales from 50 days to 1 year. These findings are in good agreement with the direct response mechanism described herein.

When the background circulation from the Florida Current, Antilles Current, and Gulf Stream is included in experiments EdFC-E0x, ocean circulation changes in the Florida Straits are also initially associated with a broad Rossby wave response directly excited by the prescribed eddy. In this case study, however, drainage of the eddies is mostly diverted northward by the Antilles Current. Therefore, even though prescribed eddies seem to play a negligible role in amplifying the magnitude of the FC variability, one of the key results from these experiments is that open ocean eddies can perturb the phase of the variability, and indirectly modulate the phase of the 


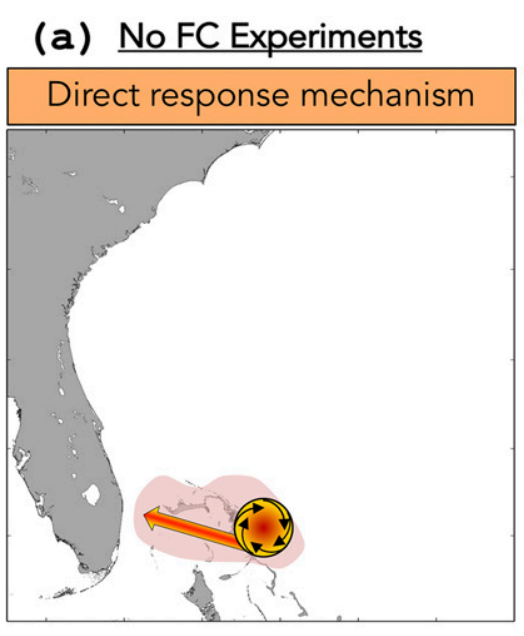

(b) With FC Experiments

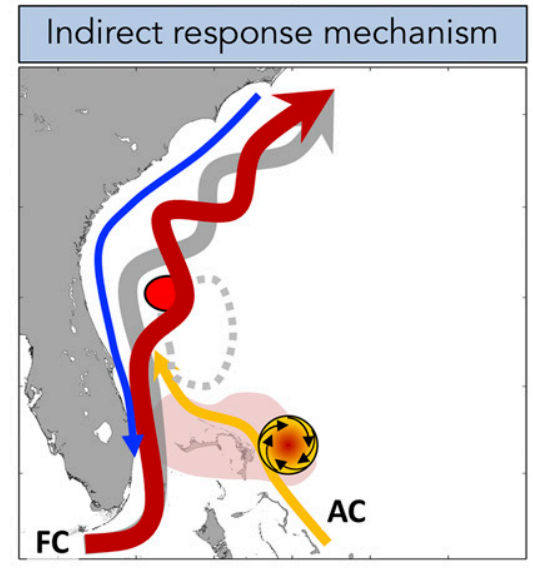

FIG. 11. Schematic diagram summarizing the role of the two mechanisms uncovered in this study, (a) the direct response mechanism, and (b) the indirect response mechanism, both linking open ocean eddy-like signals with changes in the Florida Straits variability.

FC transport through changes in the SHA variability along the coastal waveguide. Therefore, we refer to this process as the "indirect response mechanism" (Fig. 11b).

The results show that this indirect response mechanism is closely associated with phase modulation of the intrinsic FC variability. Coastally trapped signals triggered by the interaction of Gulf Stream meanders with the continental slope (e.g., Fig. S6) were one of the key processes driving the intrinsic variability in experiments developed with a realistic representation of the Florida Current, Antilles Current, and Gulf Stream (experiments EdFC-E0x and CNTR). Coastally trapped signals were more often traced to the proximity of Cape Hatteras, which is an area characterized by elevated levels of variability due to intense Gulf Stream meandering (e.g., Watts and Johns 1982). Huthnance (1992) suggested that coastally trapped waves can be generated by a large variety of mechanisms over the continental shelf and slope, including scattering by irregularities in the shelf, and generation by oceanic eddies offshore. The main mechanism triggering these signals consists of fluctuating offshore forcing in the form of pressure anomalies, from which waves will respond to the off-shelf forcing according to the similarities between the length and time scales in the forcing and the dispersion curve of free coastally trapped waves (Chapman and Brink 1987). The transmission of offshore signals to the shelf is further affected by other parameters, such as the slope, shelf topography, stratification, and friction (e.g., Ezer 2016). The resulting response can be either mostly barotropic (Chapman and Brink 1987), or given by a hybrid baroclinic Kelvin wave/barotropic continental shelf wave, for which the structure depends on the steepness of the topography and strength of stratification (Huthnance 1978). Previous analysis along the southeast U.S. coast suggested that the Charleston Bump located at approximately $32^{\circ} \mathrm{N}$ indeed plays an important role in driving the amplification of both barotropic and baroclinic instabilities leading to Gulf Stream meandering (Dewar and Bane 1985), and that further interaction between meanders and this topographic feature could trigger the southward propagating coastal signals (Oey et al. 1992). Results obtained here provide further evidence that Gulf Stream meandering onto the shelf can provide a significant source of pressure anomalies for triggering trapped waves along the coastal waveguide, and suggest that the dominant signals are consistent with first-mode baroclinic signals for the time scales considered in this study. The results reported herein are also complementary to findings by Ezer (2016), who reported that variations in Gulf streamflow can be transmitted onto the shelf by the generation of coastally trapped waves.

Once eddy-like features were included in experiments EdFC-E0x, changes in the FC variability following the initial "direct" response were mainly characterized by shifts in the phase of seasonal oscillations associated with its intrinsic variability, while the overall amplitude of the variability remained unchanged and equivalent to the control run developed in the absence of eddies. Phase modulation of seasonal oscillations in the FC transport is likely the main outcome of the indirect response mechanism forced by westward-propagating eddy-like features. Results suggest that this mechanism can include an initial influence of broad barotropic Rossby wave anomalies originating in the open ocean, 
but that it is largely dominated by complex processes that involve the nonlinear dynamics of the system through the interaction of eddy anomalies with the unstable background circulation. It has been previously shown for supercritical western boundary currents that energy is actively transported from the interior of the ocean to the mean western boundary circulation via ageostrophic pressure work divergence, while about $53 \%$ of this energy is converted back to eddy energy via turbulence production in the outer offshore layer (Lee 2001). Results obtained here showed that SHA signals from prescribed eddies were generally amplified as they interacted with other signals associated with the background circulation, and propagated northward toward Cape Hatteras. At the same time, the phase of Gulf Stream meandering diverged remarkably among the different EdFC-E0x experiments, and with respect to the control run CNTR, suggesting that small perturbations included in the EdFC-E0x could lead to large changes in the overall variability. Considering the energetic and highly nonlinear nature of the Gulf Stream, these results indicate that SHA signals originating in the ocean interior may affect the stochastic characteristic of the system, leading to changes in the phase of the meandering. In other words, the observed changes in the FC variability in EdFC-E0x are consistent with the "butterfly effect," where the introduction of a small perturbation to a nonlinear system can lead to a phase change, causing the system to evolve in a different state.

The observed changes in the SHA variability along the coastal waveguide in EdFC-E0x experiments with respect to the control run CNTR provided the key to understanding the phase modulation of the FC variability. Results showed that coastally trapped signals were largely triggered by the Gulf Stream meandering activity at Cape Hatteras. Hence, changes in the meandering forced by the nonlinear perturbations that were traced to the prescribed eddy likely played an important role in changing the coastal SHA variability. It is important to emphasize that the modulation of the FC variability observed in EdFC-E0x experiments resulted from net signals reaching the Florida Straits. In other words, the FC variability will "feel" SHA signals that reach the Florida Straits, since constructive/destructive interactions between coastally trapped signals generated at Cape Hatteras with signals generated by lateral meandering midway (e.g., at $30^{\circ} \mathrm{N}$, magenta square, Fig. 7b) may sometimes be observed. In addition, coastally trapped signals generated due to lateral meandering midway between Florida Straits and Cape Hatteras forced by eddy anomalies may have also played a role. Nevertheless, the modulation of the FC variability is linked with integrated changes in the coastal SHA variability reaching the
Straits. These results are largely complementary to findings from Domingues et al. (2016), who, based on satellite and in situ observations, reported that approximately $50 \%$ of the variance from the transient component of the FC transport was accounted for by integrated coastal SHA changes along the East Coast of the United States that were associated with westward-propagating signals.

The regional simulations developed in this study helped provide additional understanding on the role that westward-propagating eddies may play in modulating the phase of the FC variability. However, it should be acknowledged here that the simulated magnitude of the intrinsic FC variability was largely underestimated by the controlled environment adopted in our experiments (constant boundary conditions, no wind forcing). These configurations imply that large-amplitude changes in the FC transport forced by local winds (e.g., Wunsch et al. 1969; Schott et al. 1988), remote winds (e.g., DiNezio et al. 2009), storm winds (e.g., Ezer et al. 2017; Todd et al. 2018), or by upstream Loop Current dynamics in the Gulf of Mexico (e.g., Lin et al. 2009; Mildner et al. 2013) are not included in our numerical experiments. These processes were deliberately disabled in our simulations to better isolate the effect of westward-propagating eddies. In fact, when winds and boundary conditions are more realistically represented, about $80 \%$ (simulated STD $=2.6 \mathrm{~Sv}$, observations STD $=3.2 \mathrm{~Sv}$ ) of the FC transport variability is recovered by the HYCOM simulation (Kourafalou et al. 2016) that provides the average boundary conditions in our experiments. Nevertheless, the mechanism reported here is consistent with observations reported in Domingues et al. (2016), which showed that the phase of the transient component of the FC transport was indeed strongly correlated with the phase of westward-propagating signals reaching the Florida Straits. Therefore, it is likely that under more realistic ocean conditions, westward-propagating signals can also modulate the amplified FC variability forced by other processes that are not included in the simulations developed in this study.

Finally, this study has addressed some gaps in knowledge regarding the potential blocking impact of the Bahamas archipelago to signals coming from the interior, as previous studies relying on low resolution (Czeschel et al. 2012) or simplified ocean models (Pedlosky and Spall 1999; Simmons and Nof 2002) could not realistically reproduce the dynamics of the North Atlantic western boundary, given its complex topography. In this study, experiments developed without the background ocean circulation showed that signals originating in the open ocean may indeed reach the Florida Straits through Northwest Providence Channel mainly in the form of baroclinic wall-jet features. It is worth emphasizing, 
however, that experiments developed with the background flow (experiments EdFC-E0x) suggest that, under more realistic ocean conditions, the Antilles Current can act as a barrier for baroclinic signals originating in the open ocean. Given that the Antilles Current is associated with elevated levels of variability (e.g., Lee et al. 1990, 1996) and that its flow can often halt and occasionally reverse (Johns et al. 2008), it is reasonable to expect that at certain times eddies may interact directly with the boundary as in the "no background flow" case study through the direct response mechanism. Therefore, even though experiments from set SENS-E0x did not include the background ocean circulation, they are useful to highlight the potential role of the direct response mechanism for linking changes in FC flow with the open ocean variability. In fact, the mechanism described here offers an explanation for previous observations indicating that signals traveling through the Northwest Providence Channel correspond to one source of FC variability (Leaman and Molinari 1987; Leaman et al. 1987; Beal et al. 2008).

In conclusion, this study has focused on improving our understanding of the role of westward-propagating signals in driving year-to-year changes in the phase of the seasonal variability of the FC transport, which accounts for $27 \%$ of the total FC variance. This component of the FC variability is also closely associated with changes in the seasonality of the meridional heat transport (MHT) and AMOC. The approach and techniques employed here can also likely be applied to other western boundary current systems, and adjusted in order to investigate the influence of other processes and time scales driving the variability of these currents. This study shows how the application of ocean simulations based on controlled realistic numerical experiments can provide valuable information about the underlying dynamics and variability of western boundary currents.

Acknowledgments. The Regional Ocean Modeling System (ROMS) is made freely available at www.myroms.org. Ricardo Domingues acknowledges support from the University of Miami Cooperative Institute for Marine and Atmospheric Studies, and from the NOAA Atlantic Oceanographic and Meteorological Laboratory. William E. Johns acknowledges support from the National Science Foundation under Grant OCE1332978. Christopher Meinen also acknowledges support from the NOAA Atlantic Oceanographic and Meteorological Laboratory, as well as support from the NOAA-CPO Ocean Observing and Monitoring Division. The authors thank Matthieu Le Hénaff and George Halliwell for their help obtained modelling outputs from the North Atlantic HYCOM simulation, Shenfu Dong for helpful comments during earlier versions of the manuscript, and two anonymous reviewers, whose comments and suggestions helped improve the overall quality of this manuscript.

\section{APPENDIX A}

\section{Additional Details on Numerical Experiments Developed}

Experiments are carried out in a domain within $60^{\circ}-82^{\circ} \mathrm{W}$ and $21^{\circ}-37^{\circ} \mathrm{N}$ (Fig. 1). The bottom topography is derived from ETOPO-1 (Amante and Eakins 2009), which is then smoothed to control the maximum grid stiffness by setting the Beckman and Haidvogel parameter (rx0) to 0.1 , and the Haney parameter (rx1) to 2.7. These configurations of $\mathrm{rx} 0$ and $\mathrm{rx} 1$ are selected to avoid spurious and unrealistic flows resulting from pressure-gradient errors (e.g., Haney 1991; Beckmann and Haidvogel 1993), which are often small (Vmax of $\sim 1 \mathrm{~cm} \mathrm{~s}^{-1}$ ) in ROMS and defined as sigma errors of the second kind (Mellor et al. 1998). Realistic bottom topography is used at and in the proximity of the east coast of the United States (Fig. 1). The minimum bottom depth of the ocean domain is set to $10 \mathrm{~m}$, and the bathymetry in the ocean interior is simplified by setting the maximum depth to $5000 \mathrm{~m}$, with flat-bottom conditions everywhere east of $70^{\circ} \mathrm{W}$. Parameters describing the configurations of vertical layers are available in Table A1.

The following ROMS configurations are adopted for all experiments: (i) nonlinear equation of state; (ii) analytical spherical grid; (iii) centered, fourth-order advection of tracers and momentum; (iv) harmonic horizontal mixing of tracers and momentum; (v) KPP vertical mixing (Large et al. 1994); and the (vi) splines density Jacobian for the pressure gradient computation (Shchepetkin and McWilliams 2005). In addition, boundary conditions for all experiments are as follows: Flather boundary condition (Flather 1976) for the free surface; Chapman boundary conditions (Chapman 1985) for the 2D barotropic velocity; gradient boundary condition for mixing turbulent kinetic energy; and mixed radiationnudging boundary conditions (Marchesiello et al. 2001) for baroclinic velocity, temperature and salinity. Nudging time scales to boundary values are set to one day. A sponge layer with both viscosity and diffusivity progressively increased by a factor of 1-10 is also defined at the 20 points in the vicinity of all boundaries, with the exception of the inflow boundary in the Florida Straits (Fig. S7). These configurations of sponge layer, and boundary conditions allows signals to exit the domain, while enforcing boundary values for time scales 
TABLE A1. Parameters defining configuration of vertical layers on the grid used in this study.

\begin{tabular}{lcl}
\hline \hline Parameter & Value & \multicolumn{1}{c}{ Description } \\
\hline$N$ & 30 & Number of vertical layers \\
Vtransform & 2 & Transformation equation \\
Vstretching & 4 & Vertical stretching function \\
Theta_s & 4 & Surface stretching parameter \\
Theta_b & 0 & Bottom stretching parameter \\
Tcline & 10 & Critical depth $(\mathrm{m})$ \\
\hline
\end{tabular}

longer than 1 day, and also prevent the generation of spurious signals along the boundary.

Numerical experiments are initialized using fields of temperature and salinity including eddy-like westwardpropagating signals that are prescribed as small perturbations in the pycnocline depth in the ocean interior. Realistic configurations of westward-propagating signals are employed in this study based on characteristics of signals observed in the satellite altimetry record on seasonal time scales. Analysis of daily fields of gridded sea-height residuals (SHAr; annual cycle removed) from AVISO (available at http://www.aviso.oceanobs.com) in the 73-525-day band, which includes the combined semiannual and annual waves described by Polito and Liu (2003), exhibits eddy-like westward-propagating signals (Fig. S2a) that account for $42 \%$ of the total SHA variability west of $60^{\circ} \mathrm{W}$. These signals are associated with amplitudes of $\pm 15 \mathrm{~cm}$ at $27^{\circ} \mathrm{N}$ (Figs. S2a,d) and broadband spectrum, with dominant wavelengths ranging between 300 and $700 \mathrm{~km}$ (Fig. S2c). Eddy-like westward-propagating signals using these characteristics are prescribed as first baroclinic perturbations in the pycnocline depth.

\section{APPENDIX B}

\section{The Feature Model Approach}

Westward-propagating signals are prescribed in the initial condition fields as first baroclinic perturbations in the pycnocline depth. To accomplish this, we prescribe oceanographic features of interest using mathematical functions (i.e. Calado et al. 2008). Eddy-like features are constructed in this study as vertical displacements of isopycnal surfaces using two functions: (i) a modified first baroclinic mode for vertical velocity $\left[\varphi_{1 m}(x)\right.$; black line in Fig. S1e], and (ii) a Gaussian function $\left[G_{x y}\right.$; Eq. (B1); Fig. S8]. The modified first baroclinic mode is used to define the structure of the vertical displacement of individual isopycnal surfaces. The original first baroclinic mode $\left[\varphi_{1}(x)\right.$, gray line in Fig. S1e] is calculated numerically by solving the vertical baroclinic modes using a rigid-lid assumption for the mean climatological temperature and salinity profiles (Figs. S5a,b) in the domain, which are obtained from the World Ocean Atlas 2013. Parameter $\varphi_{1 m}(x)$ is then calculated by adding a linear profile with maximum value of 0.5 at the surface and minimum value of 0 at the depth associated with the maximum value observed for this mode $(\sim 1300 \mathrm{~m})$. The modification of $\varphi_{1}(x)$ was defined after extensive evaluation of different approaches, including those using the original modes with both rigid-lid, or free-surface boundary conditions, and was chosen for providing stable and realistic first baroclinic mode like upper-ocean eddy structures (Fig. S10), which in the real ocean can become surface-intensified when associated with background flows (e.g., Killworth et al. 1997), complex bottom topography (e.g., Samelson 1992; Tailleux and McWilliams 2001), or both (e.g., Aoki et al. 2009).

The Gaussian function $G_{x y}$ defines the horizontal structure and magnitude of isopycnal displacements and is calculated according to the following formula:

$$
\begin{aligned}
G_{x y}(x) & =\Delta Z_{\max } \times \exp \left[\left(-\frac{2 x e}{D_{E}}\right)^{2}\right], \text { with } \\
x & \in\left[-\frac{D_{E}}{2}, \frac{D_{E}}{2}\right] .
\end{aligned}
$$

In this equation, the parameter $D_{E}$ defines the horizontal diameter of the eddy, and $\Delta Z_{\max }$ sets the maximum vertical displacement of the pycnocline depth. If $\Delta Z_{\max }$ is negative, perturbations on isopycnal surfaces will lead to an anticyclonic eddy, while a positive $\Delta Z_{\max }$ will lead to a cyclonic eddy. Figure S8 provides a schematic overview of $G_{x y}$. Vertical perturbations on isopycnal surfaces are ultimately achieved using

$$
\begin{aligned}
& \frac{\partial \rho}{\partial t}=-w \frac{\partial \rho}{\partial z}, \\
& \rho^{\prime}=-(w \Delta t) \frac{\partial \rho}{\partial z}, \quad \text { and } \\
& \rho^{\prime}=-(\Delta Z) \frac{\partial \rho}{\partial z},
\end{aligned}
$$

where the vertical perturbation $\Delta Z$ is obtained as

$$
\Delta Z(x, z)=G_{x y}(x) \times \varphi_{1 m}(z) .
$$

Application of Eq. (B3) on a circular grid using the Gaussian function $G_{x y}(x)$ results in an eddy-like vertical perturbation on isopycnal surfaces. Figure $S 9$ shows an example of the temperature, salinity, and density structure of a single anticyclonic eddy prescribed at $27^{\circ} \mathrm{N}, 75^{\circ} \mathrm{W}$, 
using $D_{E}$ equal to $150 \mathrm{~km}$ and $\Delta Z_{\max }$ equal to $300 \mathrm{~m}$. A similar method can be used to prescribe perturbations on isopycnal surfaces using different horizontal shapes (e.g., asymmetrical features), which can be accomplished by replacing the original $G_{x y}(x)$ function in Eq. (B3) by another horizontal function of interest. For example, the Gaussian function may be replaced by a field function derived from satellite-altimetry observations. This approach described above is used to introduce perturbations in the initial temperature and salinity fields that are configured according to the specific characteristics of experiments developed in this study. All experiments are spun up from rest using ROMS in the diagnostic mode, allowing the geostrophic adjustment of the velocity field to prescribed density anomalies (Fig. S10). Additional details of experiments developed in this study are presented in appendix A.

\section{REFERENCES}

Amante, C., and B. W. Eakins, 2009: ETOPO1 1 arc-minute global relief model: Procedures, data sources and analysis. NOAA Tech. Memo. NESDIS NGDC-24, 25 pp., https://www.ngdc.noaa.gov/ $\mathrm{mgg} / \mathrm{global} / \mathrm{relief} /$ ETOPO1/docs/ETOPO1.pdf.

Aoki, K., A. Kubokawa, H. Sasaki, and Y. Sasai, 2009: Midlatitude baroclinic Rossby waves in a high-resolution OGCM simulation. J. Phys. Oceanogr., 39, 2264-2279, https://doi.org/ 10.1175/2009JPO4137.1.

Atkinson, C., H. Bryden, J. Hirschi, and T. Kanzow, 2010: On the seasonal cycles and variability of Florida Straits, Ekman and Sverdrup transports at $26^{\circ} \mathrm{N}$ in the Atlantic Ocean. Ocean Sci., 6, 837-859, https://doi.org/10.5194/os-6-837-2010.

Baringer, M. O., and J. C. Larsen, 2001: Sixteen years of Florida Current transport at $27^{\circ}$ N. Geophys. Res. Lett., 28, 3179-3182, https://doi.org/10.1029/2001GL013246.

Beal, L. M., J. M. Hummon, E. Williams, O. B. Brown, W. Baringer, and E. J. Kearns, 2008: Five years of Florida Current structure and transport from the Royal Caribbean Cruise Ship Explorer of the Seas. J. Geophys. Res. Oceans, 113, C06001, https://doi.org/ 10.1029/2007JC004154.

Beckmann, A., and D. B. Haidvogel, 1993: Numerical simulation of flow around a tall isolated seamount. Part I: Problem formulation and model accuracy. J. Phys. Oceanogr., 23, 1736-1753, https://doi.org/10.1175/1520-0485(1993) $023<1736$ :NSOFAA $>2.0$. CO; 2 .

Boning, C. W., and R. G. Budich, 1991: Seasonal transport variation in the western subtropical North-Atlantic: Experiments with an eddy-resolving model. J. Phys. Oceanogr., 21, 1271-1289, https://doi.org/10.1175/1520-0485(1991)021<1271:STVITW> 2.0.CO;2.

Bryden, H. L., W. E. Johns, and P. M. Saunders, 2005: Deep western boundary current east of Abaco: Mean structure and transport. J. Mar. Res., 63, 35-57, https://doi.org/10.1357/ 0022240053693806.

Calado, L., A. Gangopadhyay, and I. Silveira, 2008: Feature-oriented regional modeling and simulations (FORMS) for the western South Atlantic: Southeastern Brazil region. Ocean Modell., 25, 48-64, https://doi.org/10.1016/j.ocemod.2008.06.007.
Chapman, D. C., 1985: Numerical treatment of cross-shelf open boundaries in a barotropic coastal ocean model. J. Phys. Oceanogr., 15, 1060-1075, https://doi.org/10.1175/1520-0485(1985) 015<1060:NTOCSO > 2.0.CO;2.

__ , and K. H. Brink, 1987: Shelf and slope circulation induced by fluctuating offshore forcing. J. Geophys. Res. Oceans, 92 , 11 741-11759, https://doi.org/10.1029/JC092iC11p11741.

Czeschel, L., C. Eden, and R. J. Greatbatch, 2012: On the driving mechanism of the annual cycle of the Florida Current transport. J. Phys. Oceanogr., 42, 824-839, https://doi.org/10.1175/ JPO-D-11-0109.1.

Dewar, W. K., and J. M. Bane Jr., 1985: Subsurface energetics of the Gulf Stream near the Charleston Bump. J. Phys. Oceanogr., 15, 1771-1789, https://doi.org/10.1175/1520-0485(1985) 015<1771:SEOTGS $>2.0$.CO;2.

DiNezio, P. N., L. J. Gramer, W. E. Johns, C. S. Meinen, and M. O. Baringer, 2009: Observed interannual variability of the Florida Current: Wind forcing and the North Atlantic Oscillation. J. Phys. Oceanogr., 39, 721-736, https://doi.org/10.1175/ 2008JPO4001.1.

Domingues, R., M. Baringer, and G. Goni, 2016: Remote sources for year-to-year changes in the seasonality of the Florida Current transport. J. Geophys. Res. Oceans, 121, 7547-7559, https://doi.org/10.1002/2016JC012070.

Elipot, S., C. Hughes, S. Olhede, and J. Toole, 2013: Coherence of western boundary pressure at the RAPID WAVE Array: boundary wave adjustments or Deep Western Boundary Current advection? J. Phys. Oceanogr., 43, 744-765, https:// doi.org/10.1175/JPO-D-12-067.1.

Ezer, T., 2013: Sea level rise, spatially uneven and temporally unsteady: Why the US East Coast, the global tide gauge record, and the global altimeter data show different trends. Geophys. Res. Lett., 40, 5439-5444, https://doi.org/10.1002/2013GL057952.

_ 2016: Can the Gulf Stream induce coherent short-term fluctuations in sea level along the US East Coast? A modeling study. Ocean Dyn., 66, 207-220, https://doi.org/10.1007/s10236016-0928-0.

— East Coast: On the impact of sea-level rise, tides, storms, the Gulf Stream, and the North Atlantic oscillations. Earth's Future, 2, 362-382, https://doi.org/10.1002/2014EF000252.

- — , and R. Tuleya, 2017: Observations and operational model simulations reveal the impact of Hurricane Matthew (2016) on the Gulf Stream and coastal sea level. Dyn. Atmos. Oceans, 80, 124-138, https://doi.org/10.1016/j.dynatmoce.2017.10.006.

Flather, R., 1976: A tidal model of the northwest European continental shelf. Mem. Soc. Roy. Sci. Liege, 10 (6), 141-164.

Frajka-Williams, E., W. Johns, C. Meinen, L. Beal, and S. Cunningham, 2013: Eddy impacts on the Florida Current. Geophys. Res. Lett., 40, 349-353, https://doi.org/10.1002/grl.50115.

Haney, R. L., 1991: On the pressure gradient force over steep topography in sigma coordinate ocean models. J. Phys. Oceanogr., 21, 610-619, https://doi.org/10.1175/1520-0485(1991) $021<0610$ :OTPGFO $>2.0 . \mathrm{CO} ; 2$.

Huthnance, J., 1978: On Coastal trapped waves: Analysis and numerical calculation by inverse iteration. J. Phys. Oceanogr., 8, 74-92, https://doi.org/10.1175/1520-0485(1978)008<0074: OCTWAA $>2.0 . \mathrm{CO} ; 2$.

- 1992: Extensive slope currents and the ocean-shelf boundary. Prog. Oceanogr., 29, 161-196, https://doi.org/10.1016/00796611(92)90023-S.

Johns, W. E., and D. Watts, 1986: Time scales and structure of topographic Rossby waves and meanders in the deep Gulf 
Stream. J. Mar. Res., 44, 267-290, https://doi.org/10.1357/ 002224086788405356.

_ , L. Beal, M. Baringer, J. Molina, S. Cunningham, T. Kanzow, and D. Rayner, 2008: Variability of shallow and deep western boundary currents off the Bahamas during 2004-05: Results from the $26 \mathrm{~N}$ RAPID-MOC array. J. Phys. Oceanogr., 38, 605-623, https://doi.org/10.1175/2007JPO3791.1.

Johnson, R. W., 2001: An introduction to the bootstrap. Teach. Stat., 23, 49-54, https://doi.org/10.1111/1467-9639.00050.

Kanzow, T., H. Johnson, D. Marshall, S. Cunningham, J.-M. Hirschi, A. Mujahid, H. Bryden, and W. Johns, 2009: Basinwide integrated volume transports in an eddy-filled ocean. J. Phys. Oceanogr., 39, 3091-3110, https://doi.org/10.1175/2009JPO4185.1.

Killworth, P. D., D. B. Chelton, and R. A. de Szoeke, 1997: The speed of observed and theoretical long extratropical planetary waves. J. Phys. Oceanogr., 27, 1946-1966, https://doi.org/ 10.1175/1520-0485(1997)027<1946:TSOOAT>2.0.CO;2.

Kourafalou, V. H., Y. S. Androulidakis, G. R. Halliwell, H. Kang, M. M. Mehari, M. Le Henaff, R. Atlas, and R. Lumpkin, 2016: North Atlantic Ocean OSSE system development: Nature Run evaluation and application to hurricane interaction with the Gulf Stream. Prog. Oceanogr., 148, 1-25, https://doi.org/ 10.1016/j.pocean.2016.09.001.

Large, W. G., J. C. McWilliams, and S. C. Doney, 1994: Oceanic vertical mixing: A review and a model with a nonlocal boundary layer parameterization. Rev. Geophys., 32, 363-403, https://doi.org/10.1029/94RG01872.

Leaman, K. D., and R. L. Molinari, 1987: Topographic modification of the Florida Current by Little Bahama and Great Bahama Banks. J. Phys. Oceanogr., 17, 1724-1736, https://doi.org/10.1175/ 1520-0485(1987)017<1724:TMOTFC $>2.0 . C O ; 2$

,-- , and P. S. Vertes, 1987: Structure and variability of the Florida Current at $27^{\circ} \mathrm{N}$ : April 1982-July 1984. J. Phys. Oceanogr., 17, 565-583, https://doi.org/10.1175/1520-0485(1987)017<0565: SAVOTF $>2.0 . \mathrm{CO} ; 2$.

Lee, S.-K., 2001: On the structure of supercritical western boundary currents. Dyn. Atmos. Oceans, 33, 303-319, https://doi.org/ 10.1016/S0377-0265(01)00056-2.

_ front and its thermocline layer. J. Mar. Res., 52, 837-863, https://doi.org/10.1357/0022240943076920.

Lee, T. N., W. Johns, R. Zantopp, and F. Schott, 1990: Western boundary current structure and variability east of Abaco, Bahamas at $26.5^{\circ}$ N. J. Phys. Oceanogr., 20, 446-466, https:// doi.org/10.1175/1520-0485(1990)020<0446:WBCSAV $>$ 2.0.CO;2.

_ , W. E. Johns, R. J. Zantopp, and E. R. Fillenbaum, 1996: Moored observations of western boundary current variability and thermohaline circulation at $26.5^{\circ} \mathrm{N}$ in the subtropical North Atlantic. J. Phys. Oceanogr., 26, 962-983, https://doi.org/10.1175/ 1520-0485(1996)026<0962:MOOWBC >2.0.CO;2.

Lin, Y., R. J. Greatbatch, and J. Sheng, 2009: A model study of the vertically integrated transport variability through the Yucatan Channel: Role of Loop Current evolution and flow compensation around Cuba. J. Geophys. Res., 114, C08003, https:// doi.org/10.1029/2008JC005199.

Locarnini, R., and Coauthors, 2013: Temperature. Vol. 1, World Ocean Atlas 2013, NOAA Atlas NESDIS 73, 40 pp., http:// data.nodc.noaa.gov/woa/WOA13/DOC/woa13_vol1.pdf.

Marchesiello, P., J. C. McWilliams, and A. Shchepetkin, 2001: Open boundary conditions for long-term integration of regional oceanic models. Ocean Modell., 3, 1-20, https://doi.org/ 10.1016/S1463-5003(00)00013-5.
Meinen, C. S., and D. S. Luther, 2016: Structure, transport, and vertical coherence of the Gulf Stream from the Straits of Florida to the Southeast Newfoundland Ridge. Deep-Sea Res. I, 111, 16-33, https://doi.org/10.1016/j.dsr.2016.02.002.

M. O. Baringer, and R. F. Garcia, 2010: Florida Current transport variability: An analysis of annual and longer-period signals. Deep-Sea Res. I, 57, 835-846, https://doi.org/10.1016/ j.dsr.2010.04.001.

Mellor, G. L., L. Y. Oey, and T. Ezer, 1998: Sigma coordinate pressure gradient errors and the seamount problem. J. Atmos. Oceanic Technol., 15, 1122-1131, https://doi.org/10.1175/15200426(1998)015<1122:SCPGEA > 2.0.CO;2.

Mildner, T. C., C. Eden, and L. Czeschel, 2013: Revisiting the relationship between Loop Current rings and Florida Current transport variability. J. Geophys. Res. Oceans, 118, 6648-6657, https://doi.org/10.1002/2013JC009109.

Milliff, R. F., and J. C. McWilliams, 1994: The evolution of boundary pressure in ocean basins. J. Phys. Oceanogr., 24, 1317-1338, https://doi.org/10.1175/1520-0485(1994)024<1317:TEOBPI> 2.0. $\mathrm{CO} ; 2$.

Mooers, C. N. K., C. S. Meinen, M. O. Baringer, I. Bang, R. Rhodes, C. N. Barron, and F. Bub, 2005: Cross validating ocean prediction and monitoring systems. Eos, Trans. Amer. Geophys. Union, 86, 269, 272-273, https://doi.org/10.1029/2005EO290002.

Niiler, P. P., and W. S. Richards, 1973: Seasonal variability of Florida current. J. Mar. Res., 31 (3), 144-167.

Nof, D., 1988: Eddy-wall interactions. J. Mar. Res., 46, 527-555, https://doi.org/10.1357/002224088785113540.

1999: Strange encounters of eddies with walls. J. Mar. Res., 57, 739-761, https://doi.org/10.1357/002224099321560555.

Oey, L. Y., T. Ezer, G. L. Mellor, and P. Chen, 1992: A model study of "bump" induced western boundary current variabilities. J. Mar. Syst., 3, 321-342, https://doi.org/10.1016/0924-7963(92) 90009-W

Pedlosky, J., and M. Spall, 1999: Rossby normal modes in basins with barriers. J. Phys. Oceanogr., 29, 2332-2349, https://doi.org/ 10.1175/1520-0485(1999)029<2332:RNMIBW >2.0.CO;2.

Pillsbury, J. E., 1887: Gulf Stream explorations-Observations of currents. U.S. Coast and Geodetic Survey Rep., Appendix 8, 173-184.

, 1890: The Gulf Stream-A description of the methods employed in the investigation, and the results of the research. U.S. Coast and Geodetic Survey Rep., Appendix 10, 461-620.

Polito, P. S., and W. T. Liu, 2003: Global characterization of Rossby waves at several spectral bands. J. Geophys. Res., 108, 3018, https://doi.org/10.1029/2000JC000607.

Richardson, W. S., and W. J. Schmitz Jr., 1965: A technique for the direct measurement of transport with application to the Straits of Florida. J. Mar. Res., 23, 172-185.

Rosenfeld, L. K., R. L. Molinari, and K. D. Leaman, 1989: Observed and modeled annual cycle of transport in the Straits of Florida and east of Abaco Island, the Bahamas $\left(26.5^{\circ} \mathrm{N}\right)$. J. Geophys. Res., 94, 4867-4878, https://doi.org/10.1029/JC094iC04p04867.

Rossby, T., C. Flagg, and K. Donohue, 2010: On the variability of Gulf Stream transport from seasonal to decadal timescales. J. Mar. Res., 68, 503-522, https://doi.org/10.1357/002224010794657128.

Samelson, R. M., 1992: Surface-intensified Rossby waves over rough topography. J. Mar. Res., 50, 367-384, https://doi.org/ 10.1357/002224092784797593.

Schott, F. A., T. N. Lee, and R. Zantopp, 1988: Variability of structure and transport of the Florida Current in the period range of days to seasonal. J. Phys. Oceanogr., 18, 1209-1230, https://doi.org/ 10.1175/1520-0485(1988)018<1209:VOSATO>2.0.CO;2. 
Shchepetkin, A. F., and J. C. McWilliams, 2005: The regional oceanic modeling system (ROMS): A split-explicit, free-surface, topography-following-coordinate oceanic model. Ocean Modell., 9, 347-404, https://doi.org/10.1016/j.ocemod.2004.08.002.

Simmons, H. L., and D. Nof, 2002: The squeezing of eddies through gaps. J. Phys. Oceanogr., 32, 314-335, https://doi.org/10.1175/ 1520-0485(2002)032<0314:TSOETG $>2.0$. CO 2 .

Stommel, H. M., 1958: The Gulf Stream: A Physical and Dynamical Description. University of California Press, 248 pp.

Sturges, W., B. G. Hong, and A. J. Clarke, 1998: Decadal wind forcing of the North Atlantic subtropical gyre. J. Phys. Oceanogr., 28, 659-668, https://doi.org/10.1175/1520-0485(1998) $028<0659$ :DWFOTN $>2.0$. CO;2.

Sweet, W. V., M. Menendez, A. Genz, J. Obeysekera, J. Park, and J. J. Marra, 2016: In tide's way: Southeast Florida's September 2015 sunny-day flood. Bull. Amer. Meteor. Soc., 97, S25-S30, https://doi.org/10.1175/BAMS-D-16-0117.1.

Tailleux, R., and J. C. McWilliams, 2001: The effect of bottom pressure decoupling on the speed of extratropical, baroclinic Rossby waves. J. Phys. Oceanogr., 31, 1461-1476, https://doi.org/10.1175/ 1520-0485(2001)031<1461:TEOBPD>2.0.CO;2.

Todd, R. E., T. G. Asher, J. Heiderich, J. M. Bane, and R. A. Luettich, 2018: Transient response of the Gulf Stream to multiple hurricanes in 2017. Geophys. Res. Lett., 45, 10 509-10 519, https:// doi.org/10.1029/2018GL079180.

Watts, D. R., and W. E. Johns, 1982: Gulf Stream meanders: Observations on propagation and growth. J. Geophys. Res., 87, 9467-9476, https://doi.org/10.1029/JC087iC12p09467.

Wunsch, C., D. Hansen, and B. Zetler, 1969: Fluctuations of the Florida Current inferred from sea level records. Deep-Sea Res., 16 (Suppl.), 447-470.

Zhao, J., and W. Johns, 2014: Wind-driven seasonal cycle of the Atlantic meridional overturning circulation. J. Phys. Oceanogr., 44, 1541-1562, https://doi.org/10.1175/JPO-D13-0144.1.

Zweng, M., and Coauthors, 2013: Salinity. Vol. 2, World Ocean Atlas 2013, NOAA Atlas NESDIS 74, 39 pp., http://data.nodc.noaa.gov/ woa/WOA13/DOC/woa13_vol2.pdf. 